\title{
Applications of quantum dots as probes in immunosensing of small-sized analytes
}

\author{
Francesc A. Esteve-Turrillas, Antonio Abad-Fuentes ${ }^{*}$
}

Department of Biotechnology, IATA-CSIC, Agustín Escardino 7, 46980 Paterna, Valencia, Spain

\begin{abstract}
Quantum dots (QDs) are semiconductor nanoparticles with very interesting optical properties, like high quantum yield or narrow and size-tuneable fluorescence spectra. Current applications of QDs are widespread, being their use as fluorescence labels in bioassays one of the

10 most promising. These nanoparticles are usually conjugated to highly specific biomolecules like antibodies, oligonucleotides, enzymes or aptamers to improve assay selectivity. In this review, QD surface passivation, conjugation to biomolecules, and purification strategies are discussed with special emphasis to the development of QD-based immunoassays for the detection of low molecular weight compounds given the relevance of this sort of analytes in health, food safety, pharmaceutical, or environmental monitoring areas. The aim of this review is to summarize the main achievements attained so far and to initialize researchers in the field of antibody-based assays employing QDs as labels, such as fluorescence-linked immunosorbent assay (FLISA), fluorescence (or Förster) resonance energy transfer (FRET), immunochromatographic methods, and immunosensors.
\end{abstract}

Keywords: antibody, conjugation, hapten, immunoassay, ELISA, fluorescence, FRET, immunosensor, quantum dot

*Corresponding author: Antonio Abad-Fuentes. Department of Biotechnology, IATA-CSIC, Agustín Escardino 7, 46980 Paterna, Valencia, Spain. Phone: +34 963900022. Email: aabad@iata.csic.es 


\section{Introduction}

Quantum dots (QDs) are semiconductor nanoparticles with particular electronic and optical properties that have been widely studied and applied in the last decade. The typical diameter of QDs is in the $1-20 \mathrm{~nm}$ range and they can contain from 100 to 100.000 atoms per nanoparticle. Some of the most attractive properties of QDs are high quantum yield, high molar extinction coefficients, broad absorption spectra, narrow and symmetric emission bands $(30-50 \mathrm{~nm})$, large effective Stokes shifts and high resistance to photobleaching and chemical degradation (Algar et al., 2010; Rosenthal et al., 2011). The special characteristics of these nanomaterials are explained by the strong confinement of electrons when the radius of the particle is smaller than the exciton Bohr radii. Different applications can be found for QDs, such as in the photovoltaic, thermoelectric or light-emitting diode industries, but their applications in life sciences have revolutionized the state of the art of many biological assays, including fluorescence-linked immunosorbent assays (FLISA), fluorescence resonance energy transfer (FRET) assays, immunosensors, DNA probes, or imaging, currently being a real alternative to the use of traditional organic dyes, enzymatic labels, or isotopic markers.

QDs are very versatile labels because their photoluminescence emission band can be easily tuneable, from the UV to the IR regions, by the selection of the particle size $(1-12 \mathrm{~nm})$ and the nature and composition of the nanoparticle, which can be synthesized with binary alloys of atoms from 12-16 (ZnS, CdS, CdSe, HgS), 13-15 (GaAs, InP, InAs, GaN) or 14-16 (PbTe, PbSe) groups (see Figure 1). Ternary alloys of CdZnS, CdSSe, InNP or InGaAs have been also synthesized with analogous properties (Medintz et al., 2005). The aforementioned versatility in the QD emission wavelength and the fact that they can be excited by a single wavelength makes possible their simultaneous use as fluorescent labels of different processes running at the same time. Moreover, the fluorescence of QDs shows a very narrow emission band, so different markers can be potentially employed in different bioassays for the detection of several compounds in multiplexing studies without spectral interferences. Most of these bioassays involve the conjugation of QDs to a selective biomolecule, like an antibody. In this sense, several QD-based

55 immunoassays have been developed for the detection and quantification of a wide range of pathogens, proteins and toxins, but only few of them have been proposed for the analysis of 
small-sized analytes (Algar et al., 2010; Biju et al., 2008; Gill et al., 2008). These challenging analytical targets, immunochemically named haptens, encompass a wide range of physicochemically different compounds like veterinary drugs, pesticide and food additive residues, persistent organic pollutants, explosives and war agents, mycotoxins, environmental and industrial contaminants, numerous metabolites in biological fluids, hormones, packaging components, drugs of abuse, etc. The analytical determination of these chemicals is largely performed by accredited laboratories that use instrumental procedures, most of them based on chromatographic separations. Considering the high number of samples that are required to be analysed and the low to moderate sample throughput and high solvent and reagent consumption of those analytical methodologies, unaffordable economical and human resources are often required. The use of immunoanalytical approaches in monitoring programmes are currently deemed feasible and useful alternatives to chromatographic instrumental procedures, based on the high sample throughput, reduced sample treatment, portability, on-site analytical capability, and the high sensitivity and selectivity generally ascribed to these rapid methods (Lee and Kennedy, 2001). Moreover, the use of immunoassays agrees with the basic principles of the Green Chemistry by minimizing residues and waste generation (Armenta et al., 2008). Accordingly, this review will pay special attention to the different procedures and methods employed for QD conjugation to antibodies and their application to the analysis of small-sized analytes.

\subsection{Evolution of quantum dot research}

Despite the first published papers concerning the properties of QDs date back to the mid-eighties, we can consider the synthesis studies by Bawendi's group as the starting point of the revolutionary use of QDs, because they first proposed a new and simple synthetic route for the

80 preparation of semiconductor nanocrystals of uniform size and shape in macroscopic amounts (Murray et al., 1993). From that time onwards, the scientific references found in the literature concerning QDs increase almost exponentially (Figure 2), with more than 4000 papers published each year over the last decade, and more than 6000 annually in the last five-year period (ISI Web of Knowledge database, Thomson Reuters). This huge productivity on the development and improvement of new applications involving QDs points out the wide acceptance by the scientific 
community of these innovative fluorescent nanoparticles due to the sound expectations of getting more sensitive, simple and robust immunosensing systems.

Later on, Alivisatos' and Nie's groups simultaneously published the coupling of QDs to different biomolecules (Bruchez et al., 1998; Chan and Nie, 1998), thus opening the door to

90 different pioneer biosensing schemes using QDs as tracers, such as i) the development of a FLISA for the determination of 2,4,6-trinitrotoluene (TNT) (Goldman et al., 2002a); ii) the design of a FRET maltose sensor (Medintz et al., 2003); iii) the use of CdSe/ZnS QDs for in vivo imaging studies (Larson et al., 2003); iv) the development of bioluminescence resonance energy transfer (BRET) applications (So et al., 2006); v) the use of semiconductor nanocrystals for the development of electrochemical (Liu et al., 2004) and electrochemiluminescent (Jie et al., 2008a) immunosensors; or vi) the recent implementation of QDs as labels in fibre-optic evanescent wave biosensors (Zhang et al., 2010a).

The classification of published scientific papers by thematic areas is shown in Figure 2. About 30\% of articles dealing with QDs have been published in Physics, 16\% in Material Sciences, $13 \%$ in Chemistry and $10 \%$ in Engineering journals, while the rest were published in areas such as Science \& Technology, Optics, Spectroscopy or Biochemistry. Considering the country of origin of these studies, most of them were carried out in the United States (26\%), People's Republic of China (13\%), Germany (13\%), Japan (11\%), and France (6\%) (ISI Web of Knowledge database, Thomson Reuters).

Finally, the article/review ratio of published papers in scientific journals is as high as 19.3, a clear indicator of the huge interest of the scientific community to spread the knowledge and advances attained with this kind of nanoparticles.

\section{Synthesis of quantum dots}

As it was previously mentioned, the synthesis of QDs dates back to the eighties, when they were first prepared by the Stranski-Krastanov or lithographic top-down techniques. However, those methods showed a lack of reproducibility, with nanoparticles heterogeneous in size and with elevated surface defects (Li, 2008). In 1993, Bawendi and co-workers introduced the currently well-common synthesis of QDs based on the injection of organometallic precursor molecules into 
115 trioctylphosphine oxide (TOPO) and trioctylphosphine (TOP) surfactants at high temperature (190-320 ㄷ) (Murray et al., 1993). Under these conditions, nucleation occurs rapidly and the nanoparticle size can be easily tuned by a simple kinetic control (see Figure 3). The resulting QDs are very hydrophobic because the nanoparticles are coated with nonpolar surfactant molecules, where the phosphine groups interact with the core of the particle and the aliphatic chains are 120 positioned to the external surface.

In 2000, Peng's group demonstrated that the presence of small amounts of impurities in the technical grade TOPO (essentially alkyl phosphonic and phosphinic acids) coordinated to cadmium and decreased the growth of particles. Accordingly, the addition of a certain amount of compounds like hexylphosphonic acid (HPA) in the reaction allowed decreasing the growth of QDs, so a very homogenous particle size distribution could be obtained. Nevertheless, the use of HPA at a concentration higher than $5 \%$ may produce rod-like nanoparticles, which does not maintain the electron confinement properties (Peng et al., 2000). Afterwards, dimethyl cadmium was replaced by other not pyrophobic, less toxic, and more stable cadmium precursors, such as oxide (Peng and Peng, 2001), acetylacetonate (Clapp et al., 2006a) or myristate (Carion et al. 2007), with no alterations in the final QD properties. Table 1 shows some of the most employed colloidal synthetic procedures with the required reagents and the main experimental conditions.

The colloidal synthesis of CdSe crystals using high temperatures and the TOP/TOPO system is one of the most refined and extended, and the so-produced QDs have been widely characterized. Nonetheless, additional synthetic procedures have been proposed using aqueous systems and lower temperatures. These methods are essentially based on the use of different cadmium or zinc inorganic salts and sodium sulphide or sodium hydrogen selenide precursors dissolved in water with different capping agents. The thiol-containing amino acid cysteine is usually employed as capping in this kind of methodology because it has a high solvation effect, where the thiol group stabilizes the QD surface and the amino acid group is oriented to the exterior, providing a net charge that allows the dissolution of QDs in water. Many other capping compounds can also be employed, such as polyphosphates (Chen and Rosenzweig, 2002), 1-thioglycerol (Chen and Rosenzweig, 2002; Vossmeyer et al., 1994), poly(N-vinyl-2-pyrrolidone) (Li et al., 2006), 3-mercaptopropionic acid (Chen et al., 2010; Wang et al. 2009b), or thyoglycolic 
acid (TGA) (Bao et al., 2004). Table 1 also shows a brief summary of the precursors and the employed conditions for most-common aqueous synthesis of QDs.

Transition-metal ion doped QDs have been widely studied and reported showing many advantages when compared to traditional QDs, such as i) high thermal and environmental stability, ii) large Stoke shifts between excitation and emission wavelengths, and iii) high excited state lifetime which allows phosphorescent measurements (Norris et al., 2001; Yang et al., 2005; Sotelo-

150 González et al., 2012). Doping of $\mathrm{Mn}$ and $\mathrm{Cu}$ ions in different QDs like Mn:ZnS, Mn:ZnSe, Mn:CdSe, Cu:ZnSe, Cu:InP/ZnSe or CdS/Mn:ZnS have been widely studied and reported (Karan et al., 2010), where Mn-doped QDs result in orange-yellow emission particles, and Cu-doped QDs give a size-tunable emission spectra depending on the size and nature of the host nanocrystals.

Purification of QDs is usually made by precipitation with methanol or ethanol, centrifugation, and removal of the supernatant, which mainly contains unreacted precursors and other impurities. Some authors use the size-selective precipitation method, where small amounts of different polar solvents (ethanol, 2-propanol, or acetone) are employed to precipitate polydisperse mixtures of CdS QDs. This procedure is repeated until monodisperse fractions are obtained (Vossmeyer et al., 1994). Dialysis is preferred in some cases to avoid difficulties in redispersing the precipitated QDs, like in the aqueous synthesis of polyphosphate-capped CdS QDs (Chen and Rosenzweig, 2002).

\subsection{Core/shell quantum dots}

Many studies have demonstrated that the passivation of CdSe nanoparticles with a ZnS, CdS or ZnSe inorganic shell strongly increases the luminescence of the QDs to a 35-50\% quantum yield (Danek et al., 1996; Hines and Guyot-Sionnest, 1996). Accordingly, the use of protecting shells on core QDs has been widely employed in the synthesis of these nanoparticles. The ZnS shell layer has additional positive effects, such as: i) protection of the CdSe core surface against oxidation; ii) reduction of $\mathrm{Cd}$ toxicity by suppressing the dissolution of free ions; iii) increase

170 in photostability; and iv) recombination of surface core defects. The ZnS shell layer directly grows onto the QD surface, but the size of the core particle is not modified, so the luminescence 
properties of the QDs are preserved and only a small shift $(<5 \mathrm{~nm})$ in the fluorescence maximum wavelength is observed.

The standard procedure to synthetize CdSe/ZnS (core/shell) QDs uses diethyl zinc (or dimethyl) and hexamethyldisilathiane in TOP/TOPO (see Table 1), so special attention must be paid to the use of organometallic compounds owing to their pyrophobic character. Nevertheless, other coating procedures have been developed by using less hazardous oleate precursors (Carion et al., 2007). The coating procedure is entirely compatible with the previous core synthesis and it can be performed with (Danek et al., 1996; Dabboussi et al., 1997) or without (Hasani et al., 2010; Hines and Guyot-Sionnest, 1996) a previous purification step with similar results, so both methods are widely accepted. The highest photoluminescence increase is obtained with a thin ZnS shell based on only 1-2 monolayers, whereas in the case of thicker shells the QD core is more stable against oxidation or extreme buffer conditions, so a compromise must be adopted between the shell thickness and the nanoparticle required properties (Medintz et al., 2005).

\subsection{Quantification of quantum dots}

The concentration of the QDs after a colloidal synthesis procedure is difficult to determine by gravimetric or elemental composition methods, considering the unknown number of ligand molecules that are conjugated to every nanoparticle. For this purpose, Peng's group provided empiric equations to estimate the extinction coefficients for CdTe, CdSe, and CdS QDs, so their concentration can be easily calculated by the Lambert-Beer's law (Yu et al., 2003). In the case of water soluble QDs, Peng's group equations have no validity, because the spectrum is affected by the employed capping compound, but also by $\mathrm{pH}$ or ionic strength of the working buffer. Alternative strategies have been recently proposed for the quantification of QDs in solution, like the single-particle counting of streptavidin-coated CdSe/ZnS QDs (Zhang and Johnson 2008a) or phage-based assays to detect mercaptoacetic acid-coated CdSe/ZnS QDs (Mardyani and Chan, 2009). 


\section{Surface functionalization}

The most extended synthesis of QDs results in very hydrophobic nanoparticles that are only soluble in non-polar solvents such as chloroform or toluene. However, almost all biological applications require the use of aqueous buffered solutions, so QDs must be modified in order to increase their water solubility while keeping their optical properties. This double purpose can be achieved by changing the surface nature of the nanoparticles, avoiding a direct modification of the particle core. Usually, water solubilisation of QDs is attained by the introduction of functional groups (carboxylate, amino, or hydroxyl) over its surface in order to have a total net charge. Additionally, this modification of the QD surface makes easy a future conjugation to biomolecules.

210 Table 2 shows the most extended strategies for the functionalization of the QD surface. They are based on two main approaches, hydrophilic ligand exchange or encapsulation using hydrophobic interactions.

First approach consists in the substitution of TOP/TOPO molecules by hydrophilic ligands that contain a thiol group and a polar substituent, so the thiol group interacts with the QD surface and replaces the TOP/TOPO ligands, while the charged groups are oriented outside, increasing the water solubility. Originally, monodentate thiols were employed as ligands, but the use of bidentate thiol groups are currently preferred because of their stronger and more robust interaction with the QD surface, being the dihydrolipoic acid (DHLA) one of the most employed ligands (Clapp et al., 2006b; Mattoussi et al., 2000).

Second approach is based on the encapsulation of the original QD, solvated by TOP/TOPO ligands, with amphiphilic polymers or phospholipids that combines both hydrophobic alkyl chains and hydrophilic groups. In this case, non-specific hydrophobic interactions are responsible for linking the alkyl chains of both, the polymer/phospholipid and the phosphine ligands, while the polar groups are place outside the nanoparticle conferring water solubility. The employed amphiphilic polymers are mostly based on a poly(maleic anhydride) backbone with a hydrophobic side chain, such as tetradecene (Pellegrino et al., 2004), octadecane (Yan et al., 2010) or dodecyl (Fernandez-Argüelles et al., 2007). These polymers coat the QD surface using an amine-type cross-linker, such as bis(hexamethylene)triamine. Recently, other polymer coatings have been 
evaluated, like alginate, chitosan, carrageenan or polyvinyl pyrrolidone, in order to obtain water soluble QDs with reduced toxicity (Peretz et al., 2011).

The two aforementioned functionalization strategies are adequate for the solubilisation of QDs in water, so the most appropriate procedure must be selected depending on the intended future application. The main difference between the two procedures is the final size of the coated QD; whereas the use of the ligand exchange strategy does not modify the particle size, encapsulation methods notably increase the particle diameter due to the size of the TOP/TOPO layer plus the polymer or phospholipid coating (see Figure 4). Additional differences between those methods are: i) monodentate thiols are very easy to synthesize, but the obtained coated-QDs aggregate in few days and have short shelf lives, while the use of bidentate thiols improves the long-term stability from weeks to years; ii) amino derivatives are adequate for working at acid $\mathrm{pH}$, while carboxylate derivatives are more tolerant to basic $\mathrm{pH}$; iii) silica and polymer/phospholipid coatings are more stable against photobleaching and they have a higher pH stability, even though large nanoparticles are obtained (20-30 nm diameter) and FRET application is disabled; and iv) large size QDs with polymer coating shows a lower toxicity for in vivo applications than small-ligand coatings (Medintz et al., 2005).

\section{Commercial quantum dots}

Several companies offer semiconductor nanocrystals of different composition, size and surface functionalization. A summary of the most relevant information about the commercially available QDs is shown in Table 3. Most commercialized QDs are composed by CdSe or CdS alloys, and they cover a wide range of fluorescence wavelengths. However, there are some exceptions, such as the availability of same-sized QDs with different emission wavelengths based on $\mathrm{CdSe}_{\mathrm{x}} \mathrm{S}_{(1-\mathrm{x})}$ alloys, or the commercialization of InGaP, PbS and other cadmium-free QDs. These nanoparticles are hydrophobic, usually dissolving in toluene, but they can be also purchased as water-soluble QDs functionalized with carboxyl, amino or hydroxyl groups. In some cases, QDs can be acquired biotinilated or bioconjugated to streptavidin and to a variety of secondary antibodies, which allow a rapid and easy development of fluorescent immunoassays. However, in the case of multiplexed studies or when the use of a QD-labelled specific protein (or 
antibody) is mandatory, bioconjugation of the QD with the required biomolecule must be carried out.

\section{Bioconjugation of quantum dots}

QDs can be conjugated with different biomolecules, such as proteins, antibodies, aptamers, oligonucleotides, etc., and as a result a unique nanoparticle is obtained bringing together the properties of both materials, i.e., the optical/electrochemical properties of QDs and the biological function of the biomolecule. Antibodies are probably the preferred biomolecules to be bonded to QDs, considering their huge specificity, affinity, and versatility in the development of different immunoassays. Moreover, the possibility to use QDs with different emission wavelength coupled to antibodies against diverse antigens makes possible the development of simultaneous multianalyte assays.

An antibody is an immunoglobulin of $150 \mathrm{kDa}$ comprising two of each type of light $(\sim 25$ $\mathrm{kDa})$ and heavy ( 50 kDa) chains covalently linked by disulphide bonds between cysteine residues. Two disulphide bonds links the heavy chains, while another one links every light chain to its respective heavy chain (see Figure 5). Conjugation of QDs to antibodies is preferentially carried out directly taking advantage of the different amino acids in the protein. However, other procedures have been developed for indirect conjugations by using a bridge-type molecule, like avidin or protein G. Whether covalent or not, conjugation should obviously preserve the specific properties of both QDs and antibodies.

The main procedures for the conjugation of QDs with antibodies are described in Figure 6 and they can be classified into four groups: i) direct conjugation of amino/carboxyl groups using active esters; ii) direct conjugation to the QD surface through the antibody thiol groups; iii) indirect conjugation using avidin as bridge protein and biotinilated antibodies; and iv) indirect conjugation using modified protein $\mathrm{G}$ as bridge protein. Obviously, the employed QDs should have been previously modified in order to gain water solubility and the required functional groups, preferably carboxylate or amino groups. 


\subsection{Conjugation by active esters}

One of the first employed conjugation procedures reported in the scientific literature was based on the classical use of active esters, where a free carboxylic group in the functionalized QDs is activated with 1-ethyl-3-(3-dimethylaminopropyl)carbodiimide (EDC) and $\mathrm{N}$-hydroxysuccinimide (NHS) and the non-purified nanoparticle is later made react with the basic amino acids of the antibody (Hua et al., 2006). This procedure is very simple, cheap, requires common reagents, and is frequently performed in an one-pot reaction; however, the reactivity of EDC is optimal in acid buffers, while carboxyl-coated QDs require a basic $\mathrm{pH}$ to be water soluble (Algar et al., 2010). Another negative aspect is that the antibody orientation is not controlled, so undesired products can be also obtained, like reaction of the QD with the paratope (or antigen binding site) of the antibody leading to poor antigen binding. Stoichiometry of the reaction (QD/antibody ratio) must be accurately controlled in order to avoid cross-linking between antibodies, and it is usually challenging to control the number of antibodies attached to a single nanoparticle, mainly when large-sized polymer-coated QDs are involved. Finally, some crosslinking and aggregation problems have been observed by some authors using this procedure (Medintz et al., 2003; Peng et al., 2009), but nonetheless the method has been widely employed by many researchers to bioconjugate, for example, QDs to specific antibodies against estradiol (Harma et al., 2007), aflatoxin (Fernandez-Argüelles et al., 2008), deoxynivalenol (Shuping et al., 2011), microcystin-LR (Zhou et al., 2011) or fluoranthene (Ye et al., 2010). EDC/NHS chemistry has been also employed in the coating of QDs to electrodes in the development of immunosensors (Jie et al., 2008b; Wang et al., 2009a), or in the coupling to the antigen 3,5,6-trichloropyridinol in an immunochromatographic assay (Zou et al., 2010).

\subsection{Conjugation by activated maleimides and fragmented antibodies}

In this procedure, a previous reduction of the antibody is required to increase reactivity. Dithiothreitol (DTT) is commonly employed for the reduction of disulphide bonds of antibodies, but the reagent concentration must be accurately adjusted in order to break only the disulphide bonds between the heavy chains without affecting those keeping together heavy and light chains, thus maintaining the antigen recognition area (see Figure 5). The so-obtained one-half antibody (75 
$\mathrm{KDa}$ ) has two thiol groups available for conjugation. QDs must be previously coated with amino-type substituents and 4-(N-maleimidomethyl)cyclohexanecarboxylic acid $\mathrm{N}$-hydrosuccinimide ester (SMCC) is commonly employed as crosslinker (0.83 nm length). The amino-coated QDs react with the succinimidyl ester group of the crosslinker, whereas the free 320 thiols of the antibody fragment attach through the maleimide group. Both reactions require neutral $\mathrm{pH}$, so special attention must be given to the solubility of amino-coated QDs. By-products and unreacted reagents can be removed using desalting columns (Xing et al., 2007). Detailed procedures can be easily obtained from the literature and the internet, and a conjugation kit based on the aforementioned methodology is currently available from Life Technologies (see Table 3).

325 The great advantage of this method is the optimal spatial orientation of the antibody fragment, because the recognition area is always oriented outside the QD and therefore to reaction medium, so the activity of the conjugated antibodies is usually higher than those obtained by the active ester method. Nevertheless, some studies have manifested a poor functionality of QD-antibody conjugates synthetized using DTT and SMCC chemistry, probably due to the complete reduction of the antibodies (Pathak et al., 2007). Recently, a study has shown that the reduction degree of antibodies only depends on the DTT concentration and not on the time and temperature of the reaction (Mahmoud et al., 2011). These authors propose a reduction of DTT concentration in order to generate a higher yield of $75 \mathrm{kDa}$ fragments. Additionally, 2-mercaptoethanolamine was suggested for a highest efficiency in $75 \mathrm{kDa}$ antibody fragment generation based on a more specific reduction of the heavy chain's disulfide bonds

\subsection{Indirect conjugation with avidin bridge}

This procedure takes advantage of the strong affinity binding between biotin and avidin. In this case, carboxyl-coated QDs (usually capped with DHLA) are employed due to the negative global charge exhibited at neutral/basic pHs. Thus, avidin (a highly positively charged protein) can be easily anchored to negatively charged QDs through electrostatic interactions. Then, avidin-coated QDs are stoichiometrically bond to biotinylated antibodies. Other biotin binding proteins have been also evaluated, such as neutravidin or streptavidin, but less satisfactory results were obtained because of the lower global positive charge of these proteins as compared with 
avidin (Goldman et al., 2002b). Nevertheless, streptavidin-coated QDs are commercially available from suitable companies (see Table 3).

Although the high stability of the involved electrostatic interactions make avidin-coated QDs conjugates very suitable for FLISA development, the so-obtained particles have considerable size as a consequence of the dimensions of QD, avidin, and the antibody, so this conjugation approach may not be adequate for FRET applications. An additional negative aspect of this strategy is that protein orientation is not strictly controlled because biotin molecules may exist close to the antibody recognition area, and also a lack of homogeneity due to the existence of hybrid conjugates with very different protein/QD ratios has sometimes been described (Medintz et al., 2003).

On-column conjugation has been proposed in order to improve homogeneity in protein/QD ratios and to avoid cross-linking of conjugates (Clapp et al., 2006b). For this purpose, avidin and maltose binding protein (MBP) appended with a positively charged leucine zipper attachment domain are simultaneously conjugated to negatively charged QDs by electrostatic assembly, and the resulting complex is immobilized on an amylose resin (Mattoussi et al., 2000). Then, biotinylated antibodies are added to the column and after a washing step the bioconjugate is eluted by maltose addition (Clapp et al., 2006b). A novel protocol intended to improve control in the conjugation stoichiometry has been recently proposed based on a previous biotinylation of QD and antibody in separate reactions, and their later conjugation via an avidin bridge (Peng et al., 2009).

\subsection{Indirect conjugation with protein G bridge}

In this case an immunoglobulin-binding biomolecule, protein $\mathrm{G}$, is employed as bridge protein between QD and antibody. In order to improve coupling efficiency, some authors have engineered protein $\mathrm{G}$ to attach a domain with a positively charged leucine zipper, thus allowing for electrostatic assembly with negatively charged QDs. The main advantages of this method are: i)

370 high stability of the bioconjugate; ii) antibody biotinylation is not required; and iii) protein $\mathrm{G}$ interacts with the constant region of the antibody and leaves the recognition area unaltered and oriented outside the QD. As in the case of avidin bridge conjugation, the number of proteins coupled to every QD is variable and different population conjugates may be synthetized (Medintz et al., 2003). 
The use of protein $G$ as bridge biomolecule has been employed in the development of FLISAs for 2,4,6-trinitrobenzene and hexahydro-1,3,5-trinitro-1,3,5-triazine explosives (Goldman et al., 2002c), and also for the simultaneous determination of four toxins: Shiga-like toxin 1, staphylococcal enterotoxin B, cholera toxin, and ricin (Goldman et al., 2004).

\subsection{Conjugation using polyhistidine peptides}

This conjugation strategy is based on the direct metal-affinity coordination of polyhistidine residues with QD zinc atoms, so a direct interaction takes places between the QD surface and the biomolecule with an appended polyhistidine tag. The great advantage of this conjugation approach is the short distance between QD and the attached protein, thus improving the FRET efficiency, while the main drawback is that engineered bioreceptors are required. The direct conjugation of CdSe/ZnS QDs with recombinant antibodies bearing polyhistidine tags have been employed for the development of fluorescent bioassays for the determination of the explosive 2,4,6-trinitrotoluene by FLISA (Goldman et al., 2005a) and FRET (Goldman et al., 2005b).

\subsection{Other considerations}

Bioconjugated QDs must be purified after the conjugation procedure in order to remove unreacted antibodies and undesired compounds.. The most general purification technique is based on liquid chromatography using size-exclusion columns and aqueous buffers, but aggregation problems and lack of resolution has been often reported (Hua et al., 2006; Trapiella-Alfonso et al., 2011b).

As mentioned above, the final antibody/QD ratio is a critical parameter in the bioassay performance. Although difficult to determine experimentally, this ratio strongly depends on the employed conjugation strategy and it can be estimated by UV/vis spectrophotometry (Kattke et al., 2011) or SDS-PAGE (Pathak et al., 2007; Shen et al. 2007). However, no information about the antibody activity is provided, and spectral interferences and synergic effects may induce wrong ratios. In fact, there is a controversy upon the effect of the conjugation over the QD optical properties. While some authors manifest that the fluorescence intensity of QD-antibody conjugates 
is lower than that of the free QD (Shen et al., 2007), in other cases a higher intensity has been reported (Clapp et al., 2006; Ye et al., 2010).

To conclude, the most adequate conjugation strategy must be selected depending on the potential application we are interested in (FLISA, FRET assay, or immunosensor), even though additional aspects should also be considered, such as simplicity, long-term stability, antibody orientation, reagent availability, etc. Table 4 shows a summary of the main advantages and drawbacks of the aforementioned evaluated strategies.

\section{Quantum dot-based fluorescent immunoassays}

The luminescence properties of QDs can be used to detect analytes by using different sort of assays. First analytical applications of QDs were based on their use as probes and sensors by measuring the enhancement or quenching of the QD luminescence. These changes in luminescence are a consequence of a direct interaction of the analyte with the QD surface, so it is widely influenced by the nanoparticle coating and the $\mathrm{pH}$ and composition of the employed buffer. This surface interaction is not specific and only small and simple molecules are able to interact with the QD surface. Trial and error strategies with extensive batches of different possible analytical targets are usually employed. Thus, numerous luminescence procedures (enhancement or quenching) have been developed for the determination of inorganic cations or anions,(Lin et al., 2007), and also for some organic molecules such as spirolactone, tiopronin, dopamine, glucose, TNT, anthracene, p-nitrophenol, 1-naphtol, methionine or enoxacin (Galian and de la Guardia, 2009).

Conjugation of QDs with antibodies was more recently proposed in order to improve the selectivity of the developed assays. Many different bioassay formats have been developed using

425 QDs as fluorescent tracers, being FLISA and FRET the most employed techniques.

\subsection{Fluorescence-linked immunosorbent assays}

Enzyme-linked immunosorbent assay (ELISA) is the most extended type of immunoassay for low molecular weight chemicals because of its simplicity, reliability, low cost and high sample throughput (Bonwick and Smith, 2004). Usually, an enzyme is conjugated to an antibody or to a 
hapten and, after a competitive immunological reaction, the signal generated by the retained enzyme is measured and correlated with the analyte concentration. Antibodies and haptens can be likewise conjugated to organic fluorescent tracers, like fluorescein or rhodamine, in order to obtain FLISAs. However, the use of fluorescent dyes in immunosorbent assays has some limitations, 435 such as low photoluminescence quantum yield and poor stability. QDs offers substantial advantages as labels over organic dyes, such as: i) broad absorption spectra; ii) very narrow emission spectra; iii) long fluorescence lifetime; and iv) improved photostability (Algar et al., 2010; Galian and de la Guardia, 2009). In fact, QD labels usually provide a 3-fold thinner spectral band, a 20-fold brightness, and a 100-fold photostability when compared to rhodamine dyes (Chan and 440 Nie, 2008). Other studies have compared the fluorescence intensity and photostability of QDs against fluorescein, concluding that the QD-based method had similar (Ruan et al., 2011) or even better (Zhao et al., 2011) sensitivity than using organic dyes, but the most important improvement was the photostability: few minutes for organic dyes versus days for QD fluorescent markers.

In the analysis of small organic molecules, the most relevant ELISA formats are: i) the 445 antibody-coated competitive ELISA, wherein a competition between the analyte and an hapten-enzyme conjugate drives the immunoreaction; and ii) the conjugate-coated competitive ELISA, which is usually carried out in two separate immunochemical reactions; first a competition between the analyte and an immobilized hapten-protein conjugate, and second a detection step with labelled-secondary antibody (Esteve-Turrillas et al., 2011; Parra et al., 2011). Consequently, 450 these two formats have been widely employed in the development of FLISAs for the analysis of haptens, replacing the enzyme by a fluorescent QD tag.

Table 5 shows the QD-based FLISA studies found in the literature for the analysis of small analytes. Most of them are based on the use of the conjugate-coated competitive format, employing commercially available QD-labelled secondary antibody conjugates (Chen et al., 455 2009a; Ding et al., 2006; Zhu et al., 2011) or home-made conjugates with ZnS/CdSe (Yuan et al., 2008) and CdTe (Chen et al., 2010b). A slight variation of the indirect competitive format was proposed that uses biotin-labelled secondary antibody in combination with QD-streptavidin conjugates in two independent steps (Sun et al., 2010). All the aforementioned procedures requires the use of secondary antibodies, so more than one step is needed in order to run the 
analysis; but if the QD is directly conjugated to the specific antibody, the analysis can be run in a single step (Figure 7). Thus, different studies have been developed using anti-hapten antibodies conjugated to QDs. First examples were reported by Goldman and co-workers (2002a, 2002c, 2005) using TNT as model analyte, where indirect conjugation strategies based on electrostatic interactions between negatively charged CdSe-ZnS QDs and positively charged avidin or recombinant protein $\mathrm{G}$ were employed. Following modification of the nanoparticles, monoclonal antibodies were bound directly to Protein G-coated QDs, or biotinylated antibodies were captured by avidin-coated QDs. Anti-TNT recombinant antibodies with a polyhistidine tag have been also directly conjugated to CdSe-ZnS QDs by histidine-zinc coordination and a sensitivity improvement was obtained when compared with previous studies (Goldman et al., 2005).

Anti-sulfamethazine antibodies were conjugated by the activated maleimide method and a FLISA was developed (Shen et al., 2007). In this case, a generic antibody was employed and other related compounds like $\mathrm{N}^{4}$-acetyl sulfamethazine, sulfadimethoxine and sulfamerazine were additionally detected. Active ester method was employed for the conjugation of anti-aflatoxin (Fernandez-Argüelles et al., 2008) and anti-fluoranthene (Ye et al., 2010) antibodies, and respective fluorescent immunoassays were developed.

Concerning the antibody-coated competitive format, just an application has been reported for hapten analysis, specifically to clenbuterol detection in pig urine. Anti-clenbuterol antibodies were immobilized on magnetic $\mathrm{Fe}_{3} \mathrm{O}_{4} / \mathrm{Au}$ nanoparticles and later incubated with the analyte and a $\mathrm{CdSe} / \mathrm{CdS}$-clenbuterol conjugate. Finally, the particles were collected by magnetic forces and the 480 fluorescence was recorded. This setup allows to concentrate the nanoparticles and to reach a very low limit of detection (LOD) and a wide lineal working range from 0.0005 to $20 \mathrm{ng} / \mathrm{mL}$ (Wang et al., 2009d).

LODs achieved using QD-based fluorescent assays are in the same range of enzymatic assays. Only few studies compare the sensitivity using different detection approaches for the same immunoassay against small-sized analytes, using exactly the same antibody and conjugates. Some studies reported a decrease in sensitivity of QD-based FLISAs as compared to their enzymatic counterparts. This fact has been ascribed to a loss in antigen binding capacity of the antibody when it is conjugated with the QD, but it also depends of the quality (affinity and 
specificity) of the employed antibody (Jamieson et al., 2007), and the signal enhancement provided

by an enzymatic label cannot be ruled out. Sensitivity was quantified for different drug assays with comparative ELISAs using QD-labelled and unlabelled antibodies. In one of those studies, the activity of the labelled antibody was determined to be $45-65 \%$ of that of the unlabelled antibody (Peng et al., 2009). However, Chen et al. (2010a, 2010b) compared QD-based FLISA with ELISA against the pesticide chlorpyrifos and they found improvements in sensitivity of $47-70 \%$. Anyhow, thanks to the high affinity of antibodies, the obtained LODs are low enough to verify compliance of products with the legislation tolerances.

\subsection{Fluorescence (or Förster) resonance energy transfer}

FRET is a powerful technique that involves the nonradiative transfer of resonant

500 fluorescence energy from an excited donor fluorophore to a ground-state acceptor fluorophore. The efficiency of the transfer depends on the degree of spectral overlap between donor emission and acceptor absorption, and on the distance between both fluorophores (Förster radius). Organic dyes and dark quenchers can be used as donors and acceptors, respectively, but they show some limitations, such as the fixed absorption/emission spectra, low chemical stability, $\mathrm{pH}$ dependence or photobleaching. However, QD nanoparticles can be employed as resonant energy donors due to: i) their size-tunable and narrow fluorescence spectra that allows a better control of the spectral overlap; ii) their wide absorption bands that permit an excitation wavelength far enough from the fluorescence signal; iii) the ability to be conjugated with different molecules and proteins; and, iv) their photostability and high quantum yield (Medintz et al., 2003).

FRET is most efficient when the distance between donors and acceptors is in the $20-60 \AA$ range, and it decreases with the sixth power of the separation distance between both fluorophores (Clapp et al., 2006a). Therefore, experimental designs must consider the anchoring of donor and acceptor particle as close as possible to maximize FRET phenomena. In this sense, QDs functionalized with small ligands (such as DHLA) and using small-sized biomolecules (like 515 recombinant or fragmented antibodies) are preferred. On the contrary, the use of micelles or amphiphilic polymer functionalized QDs and/or conjugation with bridge proteins is discouraged. 
Several studies can be found that develop FRET-based assays for the detection of low molecular weight analytes (see Table 6), using predominantly a QD as donor and an organic dye as acceptor. The simplest approach consists of assays where the direct interaction between the analyte and the QD surface promotes/inhibits the FRET phenomena. In this respect, a TNT FRET assay has been recently developed involving the electrostatic interaction between amino-terminated gold nanorods and carboxyl-terminated QDs (Xia et al., 2011). Organophosphorothioate pesticides have been analysed by using a dithizone-labelled CdTe conjugate that was initially quenched by FRET (dithizone acts as acceptor), and when the analyte was added dithizone ligands were replaced by the hydrolyzate of the respective organophosphorothioate pesticide and as consequence the QD fluorescence was restored (Zhang et al., 2010b). Also, a single-drop optical FRET sensor for the detection of polycyclic aromatic hydrocarbons (PAHs) has been developed using electrodeposited QDs on $\mathrm{TiO}_{2}$ nanotubes (Yang et al., 2010). All these strategies provide low specific assays and strong interferences are usually observed with related compounds. Thus, the incorporation of biomolecules (protein, antibody, or aptamer) to FRET designs improves considerably the selectivity of the assay.

The first proposal of a QD-based FRET bioassay for haptens employed MBP, a protein with affinity to some sugars, including cyclodextrin and maltose. It consisted of a QD-MBP as FRET donor and a $\beta$-cyclodextrin-dye conjugate as acceptor. When the analyte (maltose in this case) was added, $\beta$-cyclodextrin-dye conjugate was displaced from MBP, and FRET phenomenon is inhibited; as a consequence, concentration-dependent fluorescence was generated (Medintz et al., 2003).

The first reported immunoassay for a hapten employing QDs was reported by Goldman et al. (2005b). In that work, a TNT sensor was developed using antibody fragments conjugated to $540 \mathrm{CdSe} / \mathrm{ZnS}$ QDs by means of polyhistidine tags. Then, a dye-labelled TNT analogue quenched the QD fluorescence by induced FRET, which was proportionally recovered with the addition of TNT (see Figure 8). Antibodies can be conjugated to QDs but also with the organic dye molecule, like in the development of a FRET-based assay to analyse biotin, fluorescein, and cortisol (Nikiforov and Beechem, 2006). In that case, antigen-labelled QDs and specific antibody (or streptavidin)-Alexa 545 Fluor conjugates were employed as donor and acceptor, respectively. In the same way, a 
competitive bioassay was developed to analyse 2,4-dichlorophenoxyacetic acid in water by means of the FRET phenomena produced between the antigen-labelled QD and the Cy5.5 dye-labelled antibody (Long et al. 2012).

Aptamer-QD conjugates can be also employed for the development of FRET sensors for 550 haptens, like for cocaine, where an anti-cocaine 3'-amine-terminated nucleic acid aptamer sequence was conjugated to CdSe/ZnS QDs, and a second 5'-amine-terminated aptamer sequence was conjugated to an organic dye. The complementarities of both oligonucleotides are insufficient to form a stable complex, but in the presence of the analyte a stable cocaine-aptamer supramolecular structure is stabilized and both fluorophores get closer, inducing FRET between QD and dye (see Figure 8) (Freeman et al., 2009a).

Although QDs were initially proposed as FRET donors, some examples of QDs as acceptors can be found. QDs were considered inadequate acceptors when combined with molecular dyes as donors, because of lifetime incompatibility between QDs (>10 ns) and organic dyes (<10 ns), and light excitation continuously maintains QDs in the excited state (Algar et al., 2010). However, lanthanides (with lifetimes in the ms range) can be used as donors because time-gating avoid a direct excitation of QDs. This approach was employed for the development of an estradiol assay, where a lanthanide isothiocyanate coupled to an analyte analogue was employed as donor and a QD-antibody conjugate as acceptor, being the QD fluorescence restored with the addition of estradiol (Harma et al., 2007).

More recently, an innovative TNT sensor has been develop that uses two different size QDs as donor/acceptor system, and FRET is induced in this case by aggregation of both QDs driven by the interactions between TNT molecules and the amino groups of QD ligands (Shiraki et al., 2010). However, the aforementioned procedure shows a low selectivity because of the quenching effect can be also produced by other TNT analogues, such as 2,4-dinitrotoluene or nitrobenzene.

All the aforementioned examples of FRET-based assays have very different designs, but their main common advantage is that they allow the development of homogeneous competitive bioassays, where the signal is directly measured after just an incubation step, without the need of cumbersome washing procedures. Nevertheless, the $\mathrm{pH}$, the ionic strength, and sample 
constituents may significantly affect the FRET phenomenon, so assay conditions must be carefully controlled (Jamieson et al., 2007).

Analogous resonant energy transfer processes have also been developed, like bioluminescence resonance energy transfer (BRET) (So et al., 2006) and chemiluminescence resonance energy transfer (CRET) (Huang et al., 2006), where the excitation source is replaced by a luminescence light produced by a biological or chemical reaction, respectively, and QDs are employed as energy acceptors. In spite of the promising possibilities offered by these novel resonant energy transfer methodologies, they have been focused so far to in vivo imaging studies rather than to the development of diagnostic immunosensing devices (Frasco and Chaniotakis, 2010).

\subsection{Immunosensors and related bioanalytical systems}

Most of the described bioassays for the detection and quantification of small analytes are based on FLISA and FRET technology. However, there are other immunoanalytical platforms that have been proposed for the detection of a variety of analytes using QDs. Table 7 shows the QD-based immunoassays found in literature for low molecular weight analytes excluding FLISA and FRET assays. As it can be seen, very different assays have been reported with techniques based on immunosensors, lateral flow immunoassays or the use of immunoreaction columns.

Immunosensors can be defined as self-contained devices capable of providing specific analytical information using as biological recognition element an antibody or antibody fragment which is intimately associated with or integrated within a physicochemical transducer or transducing microsystem. Whether the degree of association or integration of the receptor with the transducer is sufficient or not as to rigorously include a particular analytical setup within the immunosensor concept is sometimes controversial, so the frontier between immunosensors and other immunoanalytical systems is frequently vague and uncertain.

The implementation of QDs in immunosensors obviously relies on the composition, optical properties and electrochemical/electrochemiluminescent characteristics of these inorganic nanoparticles. The number of published papers concerning the application of QDs for the 
development of immunosensors hardly exceeds one hundred, and just a handful deals with haptens as analytical targets.

Electrochemiluminescence $(E C L)$ is a powerful technique in analytical chemistry. In ECL, light is produced from electrochemically generated intermediates that undergo a highly exergonic reaction to generate an electronically excited state. ECL has several attractive features, including absence of a background optical signal, low cost, precise control of reaction kinetics, and opportunities to enhance intensity with nanomaterials such as metallic nanoparticles and nanotubes. Together, these features make ECL a highly sensitive and selective analytical method 610 (Forster et al., 2009). After ECL of QDs in nonaqueous (Myung et al., 2002) and aqueous (Poznyak et al., 2004; Zou and Ju, 2004) solutions was first reported, a number of immunosensors based on this sensing principle has been published. For example, Zhu's and Zhang's research groups have described QD-based immunosensors for several model proteins and clinically-relevant markers (Jie et al. 2008a, 2008b, 2010, 2011; Li et al., 2011). In all these sensing schemes, different nanocomposites comprising QDs and target-specific antibodies were coated on gold electrodes, so upon addition of the analyte the formation of the immunocomplex inhibits the ECL reaction and therefore photoluminescence intensity gradually decreases with antigen concentration. Despite these remarkable precedents, to the best of our knowledge no paper has yet been published reporting the development of an ECL immunosensor with QDs for 620 hapten detection, although application of the same sensing principles to small-sized analytes can easily be envisioned.

Photoexcitation of semiconductor QDs not only leads to luminescence properties, but the photogenerated electron-hole species may also electrically communicate with electrode surfaces (Gill et al., 2008). Unlike ECL, in the photoelectrochemical detection process light is used to excite 625 photoelectrochemically active species on the electrode and current is used as the detection signal. Some outstanding examples on the application of this sensing principle using semiconductor QDs and antibodies have been recently reported by Xu's group (Wang et al., 2009a, 2009e; Zhao et al., $2012 a, 2012 b)$. More pertinent to this review is the development of a label-free immunosensor for pentachlorophenol based on photoelectrochemical detection (Kang et al., 2010). In that work nanocrystals were deposited on the inner walls and surface of $\mathrm{TiO}_{2}$ nanotubes. Following 
treatment with chitosan and glutaraldehyde, anti-pentachlorophenol antibodies were covalently conjugated on the nanotubes so the specific interaction of the analyte with the antibodies resulted in a decrease in the photocurrent. A linear response of the immunosensor in the 1-300 $\mathrm{nM}$ range, with an impressive limit of detection of $1 \mathrm{pM}$, was reported by the authors. Additional studies in this research line should contribute to extend this immunosensing principle to other relevant haptens.

QDs as electrochemically active labels have also been employed in immunoanalytical devices. Most of the reported schemes have commonly relied on a highly sensitive electrochemical stripping measurement of the metal tag after dissolution of the QDs in acidic medium (Wang, 2007; de la Escosura-Muñiz, 2008, 2010; Guo and Dong, 2009). While most studies addressed the determination of single proteins using essentially a sandwich setup where an antibody is immobilized and the other is attached to QDs (Pinwattana et al., 2010; Chen et al., 2009c; Gu et al., 2011; Ho et al., 2009; Cui et al., 2007), examples of multiplexed applications with different antibodies coupled to semiconductor nanocrystales of different composition have also been reported (Liu et al., 2004; Zhou et al., 2010; Qian et al., 2011). Interestingly, Liu's group has developed a strategy in which silica nanospheres with uniform size and excellent dispersion properties have been used as carriers for both QDs and antibodies, thus increasing sensitivity through signal amplification (Chen et al., 2009c). Furthermore, when different detection methods have been employed, electrochemistry resulted in lower detection limits than ECL and fluorescence (Qian et al., 2010; Yuan et al., 2011). Nevertheless, despite its enormous potential for 650 the ultrasensitive detection of haptens, electrochemistry, like ECL, has not been yet applied to the immunodetection of small-sized analytes.

QDs have also been successfully integrated in immunochromatographic test strips as electrochemical (Liu et al., 2009) and photoluminescence reporters ( $\mathrm{Li}$ et al., 2010). The combination of semiconductor nanocrystals and lateral flow test strips hold the promise of resulting in portable, on-site point-of-care devices enabling the sensitive, rapid, and low-cost detection of trace amounts of relevant analytes, either proteins or haptens. Lin's group has recently reported the development of QD-based immunochromatographic assays to trichloropyridinol, a biomarker of exposure to the worldwide employed organophosphorous insecticide chlorpyrifos (Zou et al., 2010), and to cotinine, a nicotine metabolite (Nian et al., 2012). Both immunosensors are based on 
660 a competitive immunoreaction tacking place on a nitrocellulose membrane, where the analyte competes with a QD-conjugated analogue for binding to the antibodies immobilized on the test zone. Remarkably, carboxy-functionalized derivatives of the analytes were directly covalently coupled to amino-modified QDs, instead of the most extended approach of attaching protein-hapten conjugates to the nanocrystals. The opposite strategy, i.e., immobilization of the 665 protein-hapten conjugate on the test zone of the lateral flow immunostrip and antibody-coated QDs, has also been described for an assay to clenbuterol (Luo et al., 2011). Recently, silica nanoparticles coated with antibodies and QDs has been used as immunocomposites in an attempt to increase assay sensitivity (Bai et al., 2012). According to these authors, this amplification strategy provided a 10-fold more sensitive strip test than when conventional gold-based labels 670 were used. Likewise, an innovative immunochromatographic test to ochratoxin A has been reported by Xu's research group using QDs coupled to aptamers as receptors (Wang et al., 2011).

The development of flow injection immunoassays for haptens employing QDs as labels has also been described. Chouhan et al. (2010) developed such a system to methyl-parathion, an organophosphorous insecticide. Specific anti-methyl-parathion antibodies were covalently 675 immobilized on Sepharose, and the analyte and a fixed amount of a complex consisting of QDs coated with protein-hapten conjugates were sequentially passed through the column. The amount of complex not retained by the column was collected and its fluorescence determined, so a positive linear correlation between the analyte concentration and the recorded signal was obtained. Authors claimed an LOD for their immunoanalytical system that favourably compares with that of a classical competitive ELISA. The same research team has recently reported a similar system for 2,4-dichlorophenoxyacetic acid, a widely applied herbicide,(Vinayaka et al., 2009). Finally, a column gel-based immunoassay for benzo[a]pyrene has been reported by Beloglazova et al. (2011). Remarkably, BSA-hapten conjugates were coupled to three different detection labels: the enzyme HRP, colloidal gold, and QDs. After successive incubation steps on Sepharose columns 685 with immobilized antibody, cut-off levels of $5 \mathrm{pg} / \mathrm{mL}$ were obtained when HRP or QDs were used as reporters, whereas with colloidal gold the lowest concentration clearly distinguishable from the zero-dose concentration was estimated as $25 \mathrm{pg} / \mathrm{mL}$. 
Finally, Chen et al. (2009) described the development of a chip-based immunoassay for the rapid and sensitive determination of 7-aminoclonazepam, the major urinary metabolite of the benzodiazepine drug clonazepam. In that system, CdTe QDs were coated with denatured BSA to improve water solubility and then antibodies were covalently conjugated through EDC/NHS chemistry. OVA-hapten conjugates were used as competing reagents, so the detection principle was based on the mobility difference between the antibody and antibody-antigen complex. The whole procedure takes $5 \mathrm{~min}$. The method was finally applied to the determination of 7-aminoclonazepam residues in human urine, and the obtained results adequately correlated with those provided by ELISA and LC/MS/MS.

\subsection{Multiplex immunoassays}

One of the main advantages offered by immunoassays is the high specificity of the 700 antigen-antibody interaction. However, some applications require the simultaneous analysis of several analytes on the same sample. This task cannot be performed neither using enzymatic immunoassays nor using organic dye-based fluorescent assays because of the overlapping of their broad emission spectra. Thus, the use of QDs as fluorescent labels may overcome these problems, considering their unique optical properties. Consequently, multiplex immunoassays can

705 be easily developed, at least theoretically, by the conjugation of QDs of different size, and therefore with diverse fluorescence spectra, to specific antibodies against distinct analytes. The applicability of this detection principle was first demonstrated for the analysis of several toxins by using multiplexed FLISAs with QDs (Goldman et al., 2004). Similar methodologies were later developed for the analysis of hapten molecules, such as the determination of five drugs

710 (dexamethason, gentamicin, clonazepam, ceftiofur, and medroxyprogesterone) in pork muscle by means of independent and simultaneous FLISAs using specific anti-drug antibodies conjugated by the avidin-bridge strategy to different QDs (Peng et al., 2009). Likewise, Hammock's group explored the possibility of using QDs in multiplexed immunoassays by means of a microarray for the detection of 3-phenoxybenzoic acid and atrazine-mercapturate, two biomarkers of exposure to 715 the pyrethroid insecticides and to the herbicide atrazine, respectively (Nichkova et al., 2007). Similarly, two generic antibodies for sulphonamides and quinolones were labelled with different 
QDs to develop a multiplexed FLISA able to determine 20 different drugs in milk (Zhu et al., 2011). Interestingly, this multianalyte assay was used in combination with an enzymatic immunoassay for melamine analysis, thus wisely proving the compatibility of both detection methodologies. Multiplexing can also be applied to competitive FRET-based assays, such as in the simultaneous determination of biotin, fluorescein, and cortisol using antigen-labelled QDs and dye-labelled antibodies and streptavidin (Nikiforov and Beechem, 2006).

Fiber optic evanescent wave biosensing platforms hold great promise for the development of QD-based immunosensors, particularly for multianalyte determination. A noteworthy proof-of-concept was reported by Zhang et al. (2010), who immobilized four different antibodies onto the surface of a single optical fibre and, using QD-labelled antigens, samples were interrogated for the presence of fibrinogen, serum albumins (human and bovine), and human IgG.

Undoubtedly, the development of multiplexed immunoassays provides an invaluable tool for the monitoring of numerous analytes in environmental and food control programs, as well as in the clinical field, because they combine the multianalyte character of chromatographic reference procedures with the simplicity, low cost and sample throughput of antibody-based methods. Nevertheless, multiplex determination of more than 3 or 4 different analytes requires the use of deconvolution software to assign the whole fluorescence response to individual analytes.

\section{Conclusions and future trends}

The use of QDs as fluorescent markers of different biomolecules has started a wide number of biological applications such as bioassays, gene technology, cell tracking or in vivo imaging (Jamieson et al., 2007). The great acceptance of this promising technology is due to the combination of both, the excellent optical properties of QDs and the high specificity of the targeting biomolecules.

We have focused this review study in the use of QDs in the development of different immunodetection schemes capable of specifically detecting small molecule chemicals, trying to explain the main features of this novel technology and the whole process steps, from the QD synthesis and surface functionalization, to the bioconjugation and assay development. The increasing number of related published papers has shown several new applications and novel 
designs, mainly based on the development of innovative biosensors, FLISA procedures, multianalyte determinations, and homogeneous FRET sensors, because of the valuable advantages of QD compared to conventional fluorescent dyes.

The main advantages that QDs offer in immunosensing are: i) higher sensitivity and stability than organic fluorophores; ii) size tuneable emission combined with broad absorption spectra allow multiplex immunoassays; and iii) the tuneable emission spectra simplifies the design of FRET assays. On the other hand, the main drawbacks of QD nanoparticles are: i) limited functionalization of ligands; ii) variable efficiency in the bioconjugation to antibodies; and iii) multiplexed assays require a data treatment to deconvolute signals.

In our opinion the future trends and novel research related to the development of QD-based bioassays for the detection of chemicals will be oriented towards the improvement of next aspects: i) QD synthesis using smooth conditions and low toxicity reagents; ii) new coating strategies to obtain long-term stable, water-compatible, and functional QDs; iii) bioconjugation procedures with high efficiency, small size particle, and easy purification steps; iv) implementation of biomolecules with high specificity as recombinant antibodies or aptamers in the development of bioassays; and v) advances in robustness of QD-based immunosensors and extension of the developed methodologies to the detection of small-sized analytes.

\section{Acknowledgements}

Authors acknowledge the financial support of Ministerio de Educación y Ciencia (AGL2009-12940-C02/ALI) and Conselleria d'Educació de la Generalitat Valenciana (BEST/2010/133). F.A.E.T. also thanks a JAE postdoctoral contract from the Ministerio de Educación y Ciencia. 


\section{References}

Algar, W.R., Tavares, A.J., Krull, U.J., 2010. Anal. Chim. Acta 673, 1-25.

Armenta, S., Garrigues, S., de la Guardia, M., 2008. TrAC, Trends Anal. Chem. 27, 497-511.

Bai, Y., Tian, C., Wei, X., Wang, Y., Wang, D., Shi, X., 2012. RSC Advances 2, 1778-1781.

Bao, H., Gong, Y., Li, Z., Gao, M., 2004. Chem. Mater. 16, 3853-3859.

Beloglazova, N.V., Goryacheva, I.Y., Niessner, R., Knopp, D., 2011. Microchim. Acta 175, 361-367.

Biju, V., Itoh, T., Anas, A., Sujith, A., Ishikawa, M., 2008. Anal. Bioanal. Chem. 391, 2469-2495.

Bonwick, G.A., Smith, C.J., 2004. Int. J. Food Sci. Technol. 39, 817-827.

Bruchez Jr., M., Moronne, M., Gin, P., Weiss, S., Alivisatos, A.P., 1998. Science 281, 2012-2016.

Callan, J.F., Mulrooney, R.C., Kamila, S., 2008. J. Fluoresc. 18, 1157-1161.

Carion, O., Mahler, B., Pons, T., Dubertret, B., 2007. Nat. Protoc. 2, 2383-2390.

Chan, W.C.W., Nie, S., 1998. Science 281, 2016-2018.

Chen, Y., Rosenzweig, Z., 2002. Anal. Chem. 74, 5132-5138.

Chen, J.X., Xu, F., Jiang, H.Y., Hou, Y.L., Rao, Q.X., Guo, P.J., Ding, S.Y., 2009a. Food Chem. 113, $1197-1201$.

Chen, W., Peng, C.F., Jin, Z.Y., Qiao, R.R., Wang, W.Y., Zhue, S.F., Wang, L.B., Jin, Q.H., Xu, C.L., 2009b. Biosens. Bioelectron. 24, 2051-2056.

Chen, L., Chen, C., Li, R., Li, Y., Liu, S., 2009c. Chem. Commun. 2670-2672.

Chen, Y.P., Ren, H.L., Liu, N., Sai, N., Liu, X.Y., Liu, Z., Gao, Z.X., Ning, B.A., 2010a. J. Agric. Food Chem. 58, 88958903.

790 Chen, Y.P., Ning, B.A., Liu, N., Feng, Y., Liu, Z., Liu, X.Y., Gao, Z.X., 2010b. J. Environ. Sci. Health., Part B 45, 508515.

Chouhan, R.S., Vinayaka, A.C., Thakur, M.S., 2010. Anal. Bioanal. Chem. 397, 1467-1475.

Clapp, A.R., Medintz, I.L., Mattoussi, H., 2006a. Chem. Phys. Chem. 7, 47-57.

Clapp, A.R., Goldman, E.R., Mattoussi, H., 2006b. Nat. Prot. 1, 1258-1266.

Cui R., Pan, H.C., Zhu, J.J., Chen, H.Y., 2007. Anal. Chem. 79, 8494-8501.

Dabbousi, B.O., Rodriguez-Viejo, J., Mikulec, F.V., Heine, J.R., Mattoussi, H., Ober, R., Jensen, K.F., Bawendi, M.G., 1997. J. Phys. Chem. B 101, 9463-9475.

Danek, M., Jensen, K.F., Murray, C.B., Bawendi, M.G., 1996. Chem. Mater. 8, 173-180.

De la Escosura-Muñiz, Parolo, C., Merkoçi, A., 2008. TrAC, Trends Anal. Chem. 27, 568-58334.

800 De la Escosura-Muñiz, Parolo, C., Merkoçi, A., 2010. Materials Today 13, 24-34.

Ding, S.Y., Chen, J.X., Jiang, H.Y., He, J.H., Shi, W.M., Zhao, W.S., Shen, J.Z., 2006. J. Agric. Food Chem. 54, 61396142.

Dubertret, B., Skourides, P., Norris, D.J., Noireaux, V., Brivanlou, A.H., Libchaber, A., 2002. Science 298, $1759-1762$.

Duong, H.D., Rhee, J.I., 2007. Talanta 73, 899-905.

805 Esteve-Turrillas, F.A., Abad-Fuentes, A., Mercader, J.V., 2011. Food Chem. 124, 1727-1733.

Fernández-Argüelles, M.T., Yakovlev, A., Sperling, R.A., Luccardini, C., Gaillard, S., Sanz-Medel, A., Mallet, J.M., Brochon, J.C., Feltz, A., Oheim, M., Parak, W.J., 2007. Nano Lett. 7, 2613-2617.

Fernández-Argüelles, M.T., Costa-Fernández, J.M., Pereiro, R., Sanz-Medel, A., 2008. Analyst 133, 444-447.

Forster, R.J., Bertoncello, P., Keyes, T.E., 2009. Annu. Rev. Anal. Chem. 2, 359-385.

810 Frasco, M.F., Chaniotakis, N., 2010. Anal. Bioanal. Chem. 396, 229-240.

Freeman, R., Li, Y., Tel-Vered, R., Sharon, E., Elbaz, J., Willner, I., 2009a. Analyst 134, 653-656.

Freeman, R., Bahshi, L., Finder, T., Gill, R., Willner, I., 2009b. Chem. Commun. 7, 764-766.

Galian, R.E., de la Guardia, M., 2009. TrAC, Trends Anal. Chem. 28, 279-291.

Gill, R., Zayats, M., Willner, I., 2008. Angew. Chem. Int. Ed. 47, 7602-7625.

815 Goldman, E.R., Anderson, G.P., Tran, P.T., Mattoussi, H., Charles, P.T., Mauro, J.M., 2002a. Anal. Chem. $74,841-847$. 
Goldman, E.R., Balighian, E.D., Mattoussi, H., Kuno, M.K., Mauro, J.M., Tran, P.T., Anderson, G.P., 2002b. J. Am. Chem. Soc. 124, 6378-6382.

Goldman, E.R., Balighian, E.D., Kuno, M.K., Labrenz, S., Tran, P.T., Anderson, G.P., Mauro, J.M., Mattoussi, H., $2002 c$. Phys. Stat. Sol. B 229, 407-414.

820 Goldman, E.R., Clapp, A.R., Anderson, G.P., Uyeda, H.T., Mauro, J.M., Medintz, I.L., Mattoussi, H., 2004. Anal. Chem. 76, 684-688.

Goldman, E.R., Medintz, I.L., Hayhurst, A., Anderson, G.P., Mauro, J.M., Iverson, B.L., Georgiou, G., Mattoussi, H., 2005a. Anal. Chim. Acta 534, 63-67.

Goldman, E.R., Medintz, I.L., Whitley, J.L., Hayhurst, A., Clapp, A.R., Uyeda, H.T., Deschamps, J.R., Lassman, M.E., Mattoussi, H., 2005b. J. Am. Chem. Soc. 127, 6744-6751.

Gu, B., Xu, C., Yang, C., Liu, S., Wang, M., 2011. Biosens. Bioelectron. 26, 2720-2723.

Guo, S., Dong, S., 2009. TrAC, Trends Anal. Chem. 28, 96-109.

Harma, H., Soukka, T., Shavel, A., Gaponik, N., Weller, H., 2007. Anal. Chim. Acta 604, 177-183.

Hasani, M., Coto García, A.M., Costa-Fernández, J.M., Sanz-Medel, A., 2010. Sens. Actuators, B 144, $198-202$.

Ho, J.A., Lin, Y.C., Wang, L.S., Hwang, K.C., Chou, P.T., 2009. Anal. Chem. 81, 1340-1346.

Hines, M.A., Guyot-Sionnest, P., 1996. J. Phys. Chem. 100, 468-471.

Hua, X.F., Liu, T.C., Cao, Y.C., Liu, B., Wang, H.Q., Wang, J.H., Huang, Z.L., Zhao, Y.D, 2006. Anal. Bioanal. Chem. 386, 1665-1671.

Huang, X., Li, L., Qian, H., Dong, C., Ren, J., 2006. Angew. Chem. Int. Ed. 45, 5140-5143.

835 Jamieson, T., Bakhshi, R., Petrova, D., Pocock, R., Imani, M., Seifalian, A.M., 2007. Biomaterials 28, 4717-4732.

Jie, G., Zhang, J., Wang, D., Cheng, C., Chen, H.Y., Zhu, J.J., 2008a. Anal. Chem. 80, 4033-4039

Jie, G., Huang, H., Sun, X.L., Zhu, J.J., 2008b. Biosens. Bioelectron. 23, 1896-1899.

Jie, G.F, Liu, P., Zhang, S.S., 2010. Chem. Commun. 46, 1323-1325.

Jie, G., Wang, L., Zhang, S., 2011. Chem. Eur. J. 17, 641-648.

840 Jin, W.J., Costa-Fernández, J.M., Pereiro, R., Sanz-Medel, A., 2004. Anal. Chim. Acta 522, 1-8.

Jin, W.J., Fernández-Argüelles, M.T., Costa-Fernández, J.M., Pereiro, R., Sanz-Medel, A., 2005. Chem. Commun. 883-885.

Kang, Q., Yang, L., Chen, Y.F., Luo, S.L., Wen, L.F., Cai, Q.Y., Yao, S.Z., 2010. Anal. Chem. 82, 9749-9754.

Karan, N.S., Sarma, D.D., Kadam, R.M., Pradhan, N., 2010. J. Phys. Chem. Lett. 1, 2863-2866.

845 Kattke, M.D., Gao, E.J., Sapsford, K.E., Stephenson, L.D., Kumar, A., 2011. Sensors 11, 6396-6410.

Kho, R., Torres-Martínez, C.L., Mehra, R.K., 2000. J. Colloid Interface Sci. 227, 561-566.

Kim, S., Bawendi, M.G., 2003, J. Am. Chem. Soc. 125, 14652-14653.

Larson, D.R., Zipfel, W.R., Williams, R.M., Clark, S.W., Bruchez, M.P., Wise, F.W., Webb, W.W., 2003. Science 300, 1434-1436.

850 Lee, N.A., Kennedy, I.R., 2001. J. AOAC Int. 84, 1393-1406.

Li, X.H., Xie, Z.H., Min, H., Li, C.Z., Liu, M., Xian, Y., Jin, L., 2006. Electroanalysis 18, 2163-2167.

Li, H., 2008a. Synthesis and Characterization of Aqueous Quantum Dots for Biomedical Applications, Ph.D Thesis, Drexel University (Philadelphia, PA, USA).

Li, D., Li, G., Guo, W., Li, P., Wang, E., Wang, J., 2008b. Biomaterials 29, 2776-2782.

855 Li, L.L., Liu, K.P., Yang, G.H., Wang, C.M., Zhang, J.R., Zhu, J.J., 2011. Adv. Func. Mater. 21, 869-878.

Li, Z., Wang, Y., Wang, J., Tang, Z., Pounds, J.G., Lin, Y., 2010. Anal. Chem. 82, 7008-7014.

Lin, C.I., Joseph, A.K., Chang, C.K., Lee, Y.D., 2004. J. Chromatogr. A 1027, 259-262.

Lin, C.A.J., Liedl, T., Sperling, R.A., Fernández-Argüelles, M.T., Costa-Fernández, J.M., Pereiro, R., Sanz-Medel, A., Chang, W.H., Parak, W.J., 2007. J. Mater. Chem. 17, 1343-1346.

860 Lin, C.A.J., Sperling, R.A., Li, J.K., Yang, T.Y., Li, P.Y., Zanella, M., Chang, W.H., Parak, W.J., 2008. Small 4, 334-341.

Liu G., Lin, Y.Y., Wang, J., Wu, H., Wai, C.M., Lin, Y., 2007. Anal. Chem. 79, 7644-7653. 
Liu, W., Howarth, M., Greytak, A.B., Zheng, Y., Nocera, D.G., Ting, A.Y., Bawendi, M.G., 2008. J. Am. Chem. Soc. 130, 1274-1284.

Liu, P., Wang, Q., Li, X., 2009. J. Phys. Chem. C 113, 7670-7676.

Long, F., Gu, C.M., Gu, A.Z., Shi, H.C., 2012. Anal. Chem. 84, 3646-3653.

Luo, W., Li, H., Xu, H., Xiong, Y. Wei, H., Lai, W., 2011. IEEE, 1520-1524.

Mahmoud, W., Rousserie, G., Reveil, B., Tabary, T., Millot, J.M., Artemyev, M., Oleinikov, V.A., Cohen, J.H.M., Nabiev, I., Sukhanova, A., 2011. Anal. Biochem. 416, 180-185.

Mardyani, S., Chan, W.C.W., 2009. J. Mater. Chem. 19, 6321-6323.

Mattoussi, H., Mauro, J.M., Goldman, E.R., Anderson, G.P., Sundar, V.C., Mikulec, F.V., Bawendi, M.G., 2000. J. Am. Chem. Soc. 122, 12142-12150.

Medintz, I.L., Clapp, A.R., Mattoussi, H., Goldman, E.R., Fisher, B., Mauro, J.M., 2003. Nat. Mater. 2, 630-638.

Murray, C.B., Noms, D.J., Bawendi, M.G., 1993. J. Am. Chem. Soc. 115, 8706-8715.

Myung, N., Ding, Z.F., Bard, A.J., 2002. Nano Lett. 2, 1315-1319.

875 Nian, H., Wang, J., Wu, H., Lo, J.G., Chiu, K.H., Pounds, J.G., Lin, Y., 2012. Anal. Chim. Acta 713, $20-55$.

Nichkova, M., Dosev, D., Davies, A. E., Gee, S. J., Kennedy, I. M., Hammock, B. D., 2007. Anal. Lett. 40, $1423-1433$.

Nikiforov, T.T., Beechem, J.M., 2006. Anal. Biochem. 357, 68-76.

Norris, D.J., Yao, N., Charnock, F.T., Kennedy, T.A., 2001. Nano Lett. 1, 3-7.

Parra, J., Esteve-Turrillas, F.A., Abad-Somovilla, A., Agulló, C., Mercader, J.V., Abad-Fuentes, A., 2011. Anal. Biochem. 416, 82-91.

Pathak, S., Davidson, M.C., Silva, G.A., 2007. Nano Lett. 7, 1839-1845.

Peng, X., Manna, L., Yang, W., Wickham, J., Scher, E., Kadavanich, A., Alivisatos, A.P., 2000. Nature 404, 59-61.

Peng, Z.A., Peng, X., 2001. J. Am. Chem. Soc. 123, 183-184.

Peng, C.F., Li, Z.K., Zhu, Y.Y., Chen, W., Yuan, Y., Liu, L.Q., Li, Q.S., Xu, D.H., Qiao, R.R., Wang, L.B., Zhu, S.F., Jin,

Z.Y., Xu, C.L., 2009. Biosens. Bioelectron. 24, 3657-3662.

Pellegrino, T., Manna, L., Kudera, S., Liedl, T., Koktysh, D., Rogach, A.L., Keller, S., Rädler, J., Natile, G., Parak, W.J., 2004. Nano Lett. 4, 703-707.

Peretz, S., Anghel, D., Teodor, E., Stanciu, G., Stoian, C., Zgherea, G., Florea-Spiroiu, M., 2011. Part. Sci. Technol. 29, 229-241.

890 Pinwattana, K., Wang, J., Lin, C.T., Wu, H., Du, D., Lin, Y., Chailapakul, O., 2010. Biosens. Bioelectron. 26, $1109-1113$.

Poznyak, S.K., Talapin, D.V., Shevchenko, E.V., Weller, H., 2004. Nano Lett. 4, 693-698.

Qian J., Zhang C., Cao, X, Liu, S., 2010. Anal. Chem. 82, 6422-6429.

Qian, J., Dai, H., Pan, X., Liu, S., 2011. Biosens. Bioelectron. 2011, 28, 314-319.

Rosenthal, S.J., Chang, J.C., Kovtun, O., McBride, J.R., Tomlinson, I.D., 2011. Chem. Biol. 18, 10-24.

Shen, J., Xu, F., Jiang, H., Wang, Z., Tong, J., Guo, P., Ding, S., 2007. Anal. Bioanal. Chem. 389, $2243-2250$.

Shiraki, T., Tsuchiya, Y., Shinkai, S., 2010. Chem. Lett. 39, 156-158.

Shuping, Y., Xin, J., Zheng, J., Lihua, T., Are, L., Yefang, K., Junkang, L., 2011. Acta Chim. Sinica 69, 687-692.

So, M.K., Xu, C.J., Loening, A.M., Gambhir, S.S., Rao, J.H., 2006. Nat. Biotechnol. 24, 339-343.

900 Sotelo-Gonzalez, E., Fernandez-Argüelles, M.T., Costa-Fernandez, J.M., Sanz-Medel, A., 2012. Anal. Chim. Acta $120-126$.

Sun, M.M., Du, L.Y., Gao, S.Q., Bao, Y.H., Wang, S.H., 2010. Steroids 75, 400-403.

Tang, B., Cao, L.H., Xu, K.H., Zhuo, L.H., Ge, J.H., Li, Q.F., Yu, L.J., 2008. Chem. Eur. J. 14, 3637-3644.

Trapiella-Alfonso, L., Costa-Fernández, J.M., Pereiro, R., Sanz-Medel, A., 2011a. Biosens. Bioelectron. 26, 47534759.

Trapiella-Alfonso, L., Montoro Bustos, A.R., Ruiz Encinar, J., Costa-Fernández, J.M., Pereiro, R., Sanz-Medel, A., 2011b. Nanoscale 3, 954-957.

Uyeda, H.T., Medintz, I.L., Jaiswal, J.K., Simon, S.M., Mattoussi, H., 2005. J. Am. Chem. Soc. 127, 3870-3878. 
Vinayaka, A.C., Basheer, S., Thakur, M.S., 2009. Biosens. Bioelectron. 24, 1615-1620.

Vossmeyer, T., Katsikas, L., Gienig, M., Popovic, I.G., Diesner, K., Chemseddine, A., Eychmüller, A., Weller, H., 1994. J.

Phys. Chem. 98, 7665-7673.

Wang, J., 2007. Electroanalysis 19, 769-776.

Wang, G.L., Yu, P.P., Xu, J.J., Chen, H.Y., 2009a. J. Phys. Chem. C 113, 11142-11148.

Wang, C., Gao, X., Ma, Q., Su, X., 2009b. J. Mater. Chem. 19, 7016-7022.

915 Wang, S., Song, H., Ong, W.Y., Han, M.Y., Huang, D., 2009c. Nanotechnol. 20, 425102-425102.

Wang, X.L., Tao, G.H., Meng, Y.H., 2009d. Anal. Sci. 25, 1409-1413.

Wang, G.L., Xu, J.J., Chen, H.Y., Fu, S.Z., 2009e. Biosens. Bioelectron. 25, 791-796.

Wang, Y., Zeng, Q., Sun, Y., Liu, X., Tu, L., Kong, X., Buma W.J., Zhang, H., 2010. Biosens. Bioelectron. 26, $149-154$.

Wang, L., Chen, W., Ma, W., Liu, L., Ma, W., Zhao, Y., Zhu, Y., Xu, L., Kuan, H., Xu, C., 2011. Chem. Commun. 47, 1574-1576.

Xia, Y.S., Song, L., Zhu, C.Q., 2011. Anal. Chem. 83, 1401-1407.

Xing, Y., Chaudry, Q., Shen, C., Kong, K.Y., Zhau, H.E., Chung, L.W., Petros, J.A., O’Regan, R.M., Yezhelyev, M.V., Simons, J.W., Wang, M.D., Nie, S., 2007. Nat. Prot. 2, 1152-1165.

Yan, Y., Wang, S., Liu, Z., Wang, H., Huang, D., 2010. Anal. Chem. 82, 9775-9781.

925 Yang, H., Santra, S., Holloway, P.H., 2005. J. Nanosci. Nanotechnol. 5, 1364-1375.

Yang, L.X., Chen, B.B., Luo, S.L., Li, J.X., Liu, R.H., Cai, Q.Y., 2010. Environ. Sci. Technol. 44, 7884-7889.

Ye, Q.Y., Zhuang, H.S., Wang, Q.E., Zhang, J.Y., Zhou C., 2010. Chin. J. Anal. Chem. 38, 385-388.

Yu, W.W., Qu, L., Guo, W., Peng, X., 2003. Chem. Mater. 15, 2854-2860.

Yuan, Y, Xu, C, Peng, C., 2008. Luminiscence 23, 107-107.

930 Yuan, L., Hua, X., Wu, Y., Pan, X., Liu, S., 2011. Anal. Chem. 83, 6800-6809.

Zhang, C.Y., Johnson, L.W., 2008a. J. Am. Chem. Soc. 130, 3750-3751.

Zhang, Y.H., Zhang, H.S., Guo, X.F., Wang, H., 2008b. Microchem. J. 89, 142-147.

Zhang, Y., Zeng, Q., Sun, Y., Liu, X., Tu, L., Kong, X., Buma, W.J., Zhang, H., 2010a. Biosens. Bioelectron. 26, 149154.

935 Zhang, K., Mei, Q.S., Guan, G.J., Liu, B.H., Wang, S.H., Zhang, Z.P., 2010b. Anal. Chem. 82, 9579-9586.

Zhang, J., Wan, Y., Li, Y., Zhang, Q., Xu, S., Zhu, H., Shu, B., 2011. Environ. Pollut. 159, 1348-1353.

Zhao, J.J., Chen, J., Wang, Z.P., Pan, J., Huang, Y.H., 2011. Mol. Med. Rep. 4, 425-429.

Zhao, W.W., Ma, Z.Y., Yu, P.P., Dong, X.Y., Xu, J.J., Chen, H.Y., 2012a. Anal. Chem. 84, 917-923.

Zhao, W.W., Dong, X.Y., Wang, J., Kong, F.Y., Xu, J.J., Chen, H.Y., 2012b. Chem. Commun. 48, 5253-5255.

940 Zhou, F., Lu, M., Wang, W., Bian, Z.P., Zhang, J.R., Zhu, J.J., 2010. Clin. Chem. 56, 1701-1707.

Zhou, X., Meng, Y., Ma, H., Tao, G., 2011. Microchim. Acta 173, 259-266.

Zhu, K., Li, J.C., Wang, Z.H., Jiang, H.Y., Beier, R.C., Xu, F., Shen, J.Z., Ding, S.Y., 2011. Biosens. Bioelectron. 26, 2716-2719.

Zou, G., Ju, H., 2004. Anal. Chem. 76, 6871-6876.

945 Zou, Z.X., Du, D., Wang, J., Smith, J.N., Timchalk, C., Li, Y.Q., Lin, Y.H., 2010. Anal. Chem. 82, 5125-5133. 


\section{Figure Legends}

Fig. 1 Dependence of fluorescence emission wavelengths of quantum dots on their chemical composition.

950

Fig. 2 Accumulated number of published papers related to quantum dots until 2012 (ISI Web of Knowledge, Thomson Reuters). Inset: Distribution of published papers by main knowledge areas.

Fig. 3 CdSe quantum dots obtained by Peng synthesis and different heating times: 3, 5, 7, 10, $95514,20,25$ and 30 minutes.

Fig. 4 Typical particle size of an antibody (A), a QD functionalized by ligand exchange with dihydrolipoic acid (B) and a QD coated with amphiphilic polymer (C).

960 Fig. 5 Schematic representation of a typical $\lg G$ antibody and the fragments originating after reduction of disulphide bridges. Red circles show the active antigen recognition areas.

Fig. 6 Most employed strategies for the bioconjugation of QDs with antibodies. Grey boxes indicate some undesired products that can be also generated.

Fig. 7 Schematic diagram of competitive fluorescence-linked immunosorbent assay (FLISA).

Fig. 8 Example of fluorescence resonance energy transfer (FRET) sensors using a QD-antibody conjugate (A) and a QD-aptamer structure (B). 
Table 1

Examples of the most common synthesis procedures for the preparation of QDs

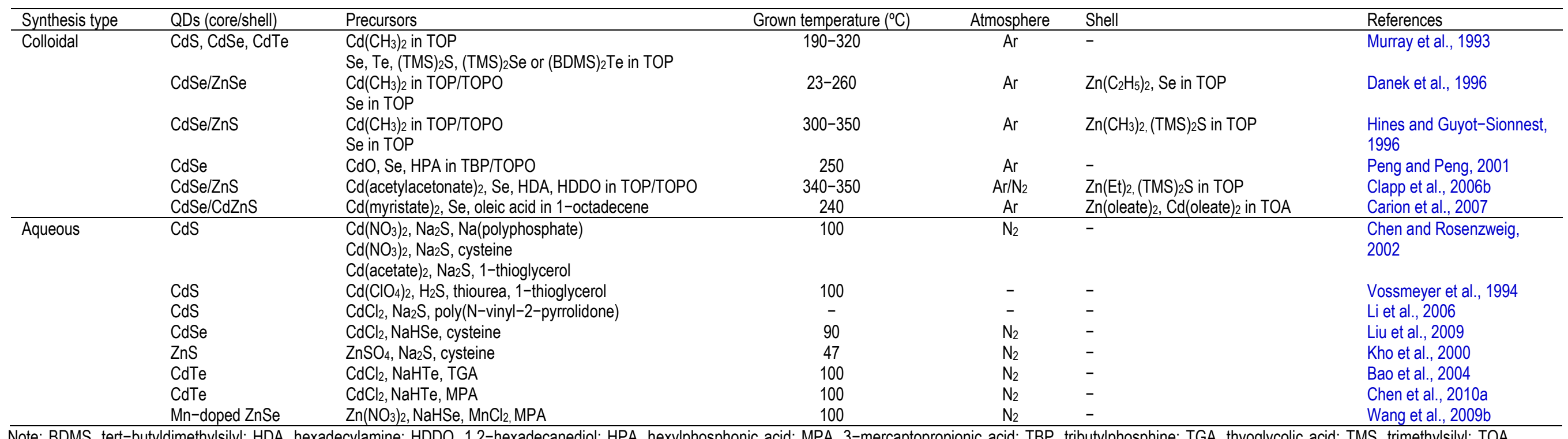

trioctylamine;TOP, trioctylphosphine; TOPO, trioctylphosphine oxide. 
Table 2

Strategies for water solubilisation of CdSe/ZnS QDs capped with TOP/TOPO.

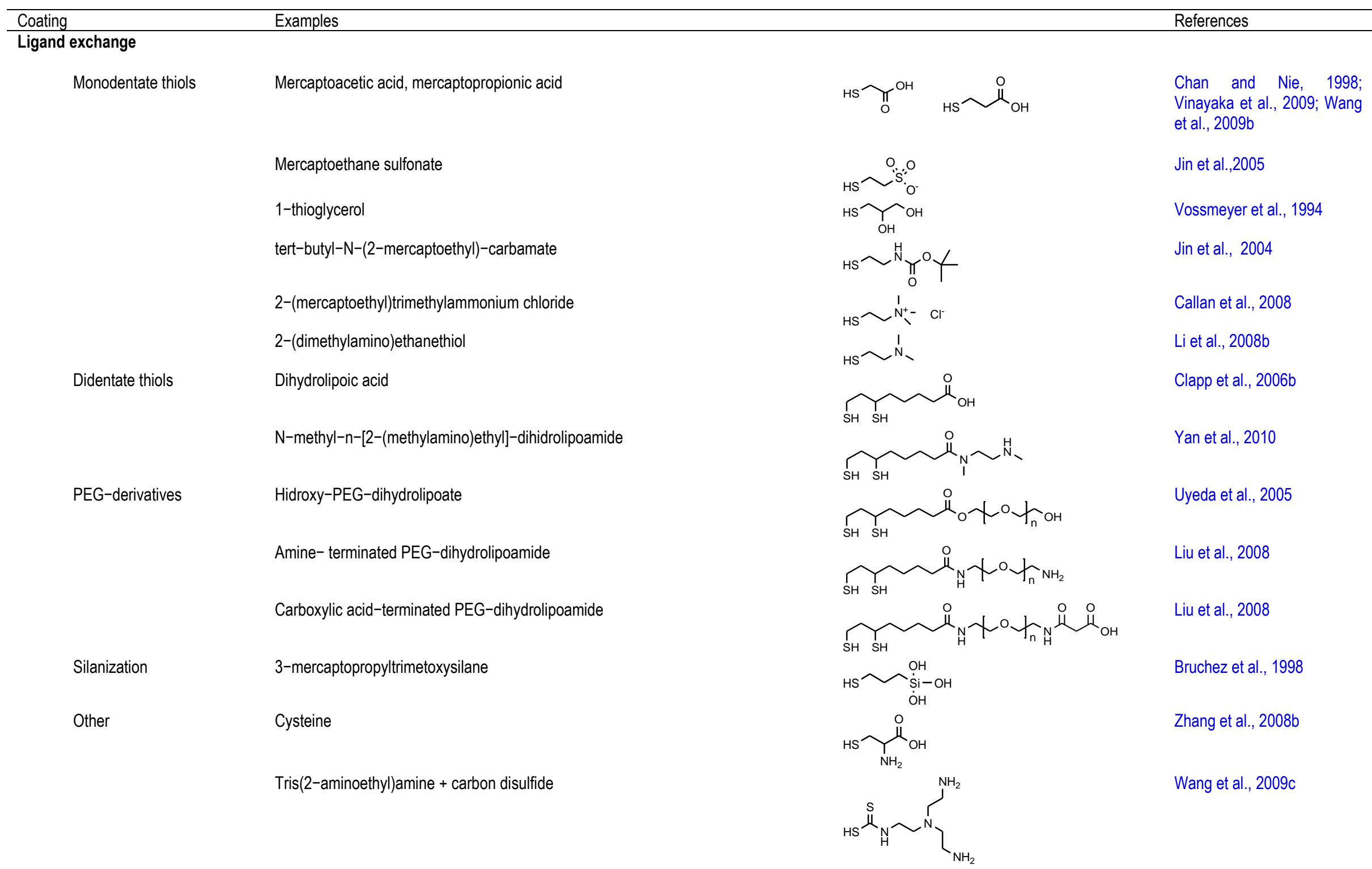




\section{Functionalized phosphines}
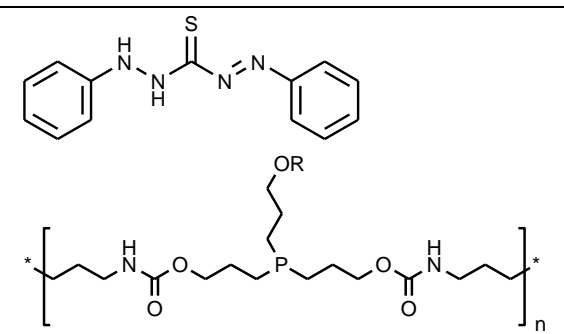

Kim and Bawendi, 2003

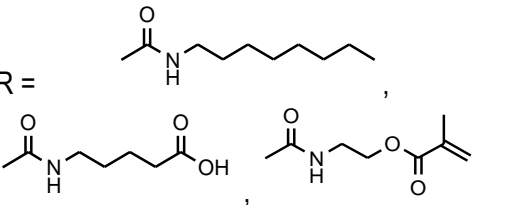

BSA-SH

Peng et al., 2009

Hydrophobic interaction

\section{Amphiphilic polymer \\ Poly(maleic anhydride alt-1-tetradecene) \\ Poly(maleic anhydride-alt-1-octadecene) \\ Poly(maleic anhydride-alt-1-dodecene)}

Denatured bovine serum albumin

\section{Phosphatidylcholine}

1,2-dipalmitoyl-sn-glycero-3-phosphoethanolamine-N-methoxy-PEG

$$
\underbrace{}_{\left(\mathrm{CH}_{2}\right)_{\mathrm{n}} \mathrm{CH}_{3}}]_{\mathrm{n}}^{\mathrm{O}}=\mathrm{O}
$$

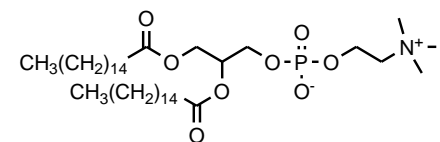

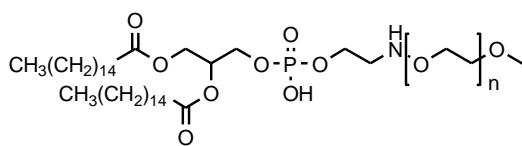

Lin et al., 2008: Pellegrino

al., 2004; Yan et al., 2010

Dubertret et al., 2002

Carion et al., 2007 


\section{Table 3}

\section{Commercially available quantum dots and most relevant information}

\begin{tabular}{|c|c|c|c|c|c|}
\hline Company & $\mathrm{QD}$ (core/shell) & $\begin{array}{l}\text { Emission } \\
\text { range }(\mathrm{nm})\end{array}$ & Funcionalized QDs & Bioconjugated with & Web page \\
\hline Attonuclei (Nantes, France) & ZnS & - & - & - & www.attonuclei.com \\
\hline CAN GmbH (Hamburg, Germany) & $\mathrm{CdSe}, \mathrm{CdSe} / \mathrm{CdS}, \mathrm{CdSe} / \mathrm{CdS} / \mathrm{ZnS}$ & $480-620$ & - & - & www.can-hamburg.de \\
\hline Crystalplex (Pittsburgh, PA, USA) & $\mathrm{CdSeS} / \mathrm{ZnS}$ & $450-685$ & Carboxyl, amino, hydroxyl & - & www.crystalplex.com \\
\hline Evident Technologies (Troy, NY, USA) & InGaP/ZnS & $650-680$ & Carboxyl, amino, biotin & - & www.evidenttech.com \\
\hline Life Technologies (Carlsbad, CA, USA) & $\mathrm{CdSe} / \mathrm{ZnS}, \mathrm{CdTe} / \mathrm{ZnS}$ & $525-800$ & Carboxyl, amino, biotin & $\begin{array}{l}\text { Streptavidin, isotype antibody, } \\
\text { anti-fluorescein, } \\
\text { anti-dinitrophenol, GAC, GAH, } \\
\text { GAM, GAR, GARt, HAM, MAH, } \\
\text { RAG, RtAM }\end{array}$ & www.lifetechnologies.com \\
\hline MKnano (Toronto, Canada) & $\begin{array}{l}\text { CdS, CdSe, CdSe/ZnS, CdTe, PbS, } \\
\text { InP/ZnS }\end{array}$ & $360-1500$ & Carboxyl & - & www.mknano.com \\
\hline Nanoco Group PLC (Manchester, England) & CdS, CdSe, CdSe/ZnS, Cd-free & $460-640$ & Carboxyl, amino & - & $\begin{array}{l}\text { www.nanocotechnologies.com } \\
\text { www.sigmaaldrich.com }\end{array}$ \\
\hline Nanomaterials \& nanofabrication laboratories (Fayetteville, AR, USA) & CdS, CdSe, CdSe/ZnS & $360-640$ & - & - & www.nn-labs.com \\
\hline Ocean Nanotech (Springdale, AR, USA) & CdSe, CdSe/ZnS & $500-630$ & Carboxyl, amino & - & www.oceannanotech.com \\
\hline PlasmaChem GmbH (Berlin, Germany) & CdTe, CdSe/ZnS, ZnCdSe/ZnS & $510-780$ & Carboxyl & & www.plasmachem.com \\
\hline Reinste Nano Ventures Pvt. Ltd (Noida, India) & CdTe, CdSe/ZnSe, ZnCdSe/ZnS & $440-780$ & Carboxyl, amino & - & www.reinste.com \\
\hline Wuhan Jiayuan QuantumDots Co., Ltd (Wuhan, China) & CdSe/ZnS & $525-625$ & Carboxyl, amino & Streptavidin, GAM, GAR & www.qds.net.cn \\
\hline
\end{tabular}

Wuhan Jiayuan QuantumDots Co., Ltd (Wuhan, China)

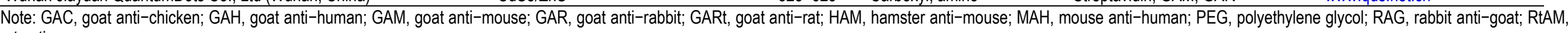
rat anti-mouse. 
Table 4

Comparison of the most employed QD-antibody conjugation procedures.

\begin{tabular}{lll}
\hline Method & Advantages & Drawbacks \\
\hline Active ester & $\checkmark$ Simple & $\times$ Aggregate formation \\
& $\checkmark$ Crosslinking & $\times$ Buffer incompatibility \\
& $\checkmark$ Common reagents & \\
& $\checkmark$ Small size & \\
& $\checkmark$ Also valid for other proteins & $\times$ Critical antibody reduction \\
Activated maleimide & $\checkmark$ Orientated antibody & $\times$ Poor functionality \\
& $\checkmark$ Small size & $\times$ Buffer incompatibility \\
Avidin bridge & & $\times$ Big size \\
& $\checkmark$ Stable interaction & $\times$ Requires protein biotinylation \\
& $\checkmark$ Streptavidin-QDs are commercially available & $\times$ On column reaction \\
Protein G bridge & $\checkmark$ Also valid for other proteins & $\times$ Heterogeneous protein/QD ratio \\
& & $\times$ Big size \\
Polyhistidine tags & $\checkmark$ Orientated antibody & $\times$ Requires engineering proteins \\
& $\checkmark$ Stable interaction & $\times$ Heterogeneous protein/QD ratio \\
\end{tabular}

Note: Detailed procedures for each conjugation methods can be found in Clapp et al. (2006), Peng et al. (2009), Xing et al. (2007) and www.lifetechnologies.com. 
Table 5

Quantum dot based fluorescence-linked immunosorbent assays (FLISAs) for haptens found in literature.

\begin{tabular}{|c|c|c|c|c|c|c|c|c|c|}
\hline Analyte & Classification & QD & QD conjugated to & $\begin{array}{l}\text { QD conjugation } \\
\text { method }\end{array}$ & Sample & Recovery (\%) & RSD (\%) & LOD (ppb) & References \\
\hline Sulfamethazine & Drug & Qdot a & Secondary antibody & Commercial & Chicken muscle & $81-117$ & $7-10$ & 1.0 & Ding et al., 2006 \\
\hline $\begin{array}{l}\text { Sulfamethazine, } \mathrm{N}^{4} \text {-acetyl sulfamethazine, } \\
\text { sulfadimethoxine, sulfamerazine }\end{array}$ & Drug & Qdot a & Specific antibody & DTT/SMCC & Milk & $94-106$ & $2-9$ & 0.6 & Shen et al., 2007 \\
\hline$\beta$-methasone & Drug & $\mathrm{ZnS} / \mathrm{CdSe}$ & Secondary antibody & - & Chicken muscle & - & - & 0.1 & Yuan et al., 2008 \\
\hline Clenbuterol & Drug & $\mathrm{CdSe} / \mathrm{CdS}$ & Antigen & - & Pig urine & $87-117$ & - & 0.0005 & $\begin{array}{l}\text { Wang et al., } \\
2009 d\end{array}$ \\
\hline Enrofloxacin & Drug & Qdot a & Secondary antibody & Commercial & Chicken muscle & $81-94$ & $10-13$ & 2.5 & $\begin{array}{l}\text { Chen et al., } \\
2009 a\end{array}$ \\
\hline $\begin{array}{l}\text { Enrofloxacin, ciprofloxacin, norfloxacin, } \\
\text { flumequine, difloxacin, sarafloxacin, } \\
\text { pefloxacin methanesulfonate, ofloxacin, } \\
\text { lomefloxacin, enoxacin, danofloxacin, oxolinic } \\
\text { acid, marbofloxacin, sulfadiazine, } \\
\text { sulfapyridine, sulfamethazine, sulfamethizole, } \\
\text { sulfamerazine, sulfamonomethoxine, }\end{array}$ & Drug & Qdot a & Secondary antibody, streptavidin & Commercial & Milk & $84-107$ & $6-14$ & 0.2 & Zhu et al., 2011 \\
\hline $\begin{array}{l}\text { Dexamethason, gentamicin, clonazepam, } \\
\text { ceftiofur, medroxyprogesterone }\end{array}$ & Drug & CdTe & Biotinylated denatured BSA & Avidin & Pork muscle & $61-87$ & $9-14$ & $0.06-0.16$ & Peng et al., 2009 \\
\hline Chlorpyrifos & Pesticide & CdTe & Secondary antibody & & Drinking water & $91-108$ & $7-15$ & 8.4 & $\begin{array}{l}\text { Chen et al., } \\
\text { 2010b }\end{array}$ \\
\hline Chlorpyrifos & Pesticide & CdTe & Streptavidin & EDC/sNHS & Drinking water & $86-105$ & $6-13$ & 3.8 & $\begin{array}{l}\text { Chen et al., } \\
2010 a\end{array}$ \\
\hline 2,4,6-trinitrotoluene & Explosive & CdSe/ZnS & Specific antibody & Protein G & - & - & - & - & $\begin{array}{l}\text { Goldman et al., } \\
2002 a\end{array}$ \\
\hline $\begin{array}{l}\text { 2,4,6-trinitrobenzene } \\
\text { hexahydro-1,3,5-trinitro-1,3,5-triazine }\end{array}$ & Explosive & $\mathrm{CdSe} / \mathrm{ZnS}$ & Specific antibody & Protein $\mathrm{G}$, avidin & - & - & - & 500 & $\begin{array}{l}\text { Goldman et al., } \\
\text { 2002c }\end{array}$ \\
\hline 2,4,6-trinitrotoluene & Explosive & $\mathrm{CdSe} / \mathrm{ZnS}$ & Recombinant antibody & Polyhistidine & - & - & - & 41 & $\begin{array}{l}\text { Goldman et al., } \\
2005 a\end{array}$ \\
\hline Aflatoxin B1 & Toxin & CdSe/ZnS & Specific antibody & EDC & - & - & - & - & $\begin{array}{l}\text { Fernández-Argüe } \\
\text { lles et al., } 2008\end{array}$ \\
\hline Deoxynivalenol & Toxin & $\mathrm{CdTe} / \mathrm{CdS}$ & Specific antibody & $\mathrm{EDC} / \mathrm{NHS}$ & Wheat flour & $99-103$ & $3-5$ & 0.038 & $\begin{array}{l}\text { Shuping et al., } \\
2011\end{array}$ \\
\hline Microcystin-LR & Toxin & $\mathrm{CdSe} / \mathrm{CdS}$ & Specific antibody & EDC & Water & $96-104$ & 1 & 0.069 & Zhou et al., 2011 \\
\hline $17 \beta$-oestradiol & Hormone & Streptavidin-QD b & Biotinylated secondary antibody & Commercial & Water & $86-113$ & - & 0.005 & Sun et al., 2010 \\
\hline Progesterone & Hormone & CdSe/ZnS & BSA-antigen & EDC & Bovine milk & $88-100$ & $1-3$ & 0.1 & $\begin{array}{l}\text { Trapiella-Alfonso } \\
\text { et al., 2011a }\end{array}$ \\
\hline Fluoranthene & $\mathrm{PAH}^{\mathrm{c}}$ & $\mathrm{CdTe}$ & Specific antibody & EDC/NHS & Water & $95-111$ & 9 & 0.013 & Ye et al., 2010 \\
\hline Perfluorooctane sulfonate & Surfactant & Streptavidin-QD b & Biotinylated DNA probe & Commercial & Water & 108 & - & 0.0025 & Zhang et al., 2011 \\
\hline
\end{tabular}

from Life Technologies (Carlsbad, CA, USA)

b from Wuhan Jiayuan QuantumDots Co., Ltd (Wuhan, China)

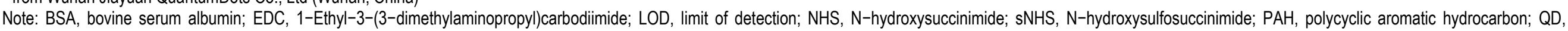
quantum dot; RSD relative standard deviation. 
Table 6

Quantum dot based fluorescence resonance energy transfer (FRET) studies for haptens found in literature.

\begin{tabular}{|c|c|c|c|c|c|c|c|c|}
\hline Analyte & Classification & Donor & Acceptor & Sample & $\begin{array}{c}\text { Recovery } \\
(\%)\end{array}$ & RSD (\%) & LOD (ppb) & References \\
\hline Maltose & Sugar & CdSe/ZnS-MBP-zb & QSY9-labelled CD & - & - & - & - & $\begin{array}{l}\text { Medintz et al., } \\
2003\end{array}$ \\
\hline 2,4,6-trinitrotoluene & Explosive & CdSe/ZnS-antibody fragment & Black hole quencher 10-labelled TNT & Soil & $40-80$ & $30-48$ & 20 & $\begin{array}{l}\text { Goldman et al., } \\
2005 b\end{array}$ \\
\hline 2,4,6-trinitrotoluene & Explosive & Amino-Qdota & Amino-Qdota & - & - & - & 0.001 & $\begin{array}{l}\text { Shiraki et al., } \\
2010\end{array}$ \\
\hline 2,4,6-trinitrotoluene & Explosive & MPA-coated CdTe/CdS & Cisteamine-labelled Au nanorods & Environmental & - & - & 0.02 & Xia et al., 2011 \\
\hline 2,4,6-trinitrotoluene & Explosive & CdS-antibody & $\begin{array}{l}\text { Ruthenium chelate-based aminoacid } \\
\text { monomer }\end{array}$ & - & - & - & - & Say et al., 2012 \\
\hline Estradiol, biotin & Hormone, vitamin & Antigen-labelled Eu and Tb isothiocyanato chelate & $\begin{array}{l}\text { CdTe-labelled streptavidin and antibody } \\
\text { fragment }\end{array}$ & - & - & $2-11$ & 0.3 & $\begin{array}{l}\text { Harma et al., } \\
2007\end{array}$ \\
\hline Biotin, fluorescein, cortisol & Hormone, other & Antigen-labelled Amino-Qdot a & $\begin{array}{l}\text { Alexa Fluor dye-labelled streptavidin and } \\
\text { antibody }\end{array}$ & - & - & - & 0.7 & $\begin{array}{l}\text { Nikiforov and } \\
\text { Beechem et al., } \\
2006\end{array}$ \\
\hline Chlorpyrifos & Pesticide & CdTe & Dithizone & Apple & $92-132$ & & 5.5 & $\begin{array}{l}\text { Zhang et al., } \\
2010 \mathrm{~b}\end{array}$ \\
\hline $\begin{array}{l}\text { 2,4-dichlorophenoxyacetic } \\
\text { acid }\end{array}$ & Pesticide & Antigen-BSA-labelled Amino-Qdota & Cy5.5-labelled antibody & Water & $91-103$ & $1-6$ & 0.1 & Long et al., 2012 \\
\hline Benzo(a)pyrene & $\mathrm{PAH}$ & CdTe & Benzo(a)pyrene & Drinking water & $92-118$ & $1-10$ & 0.004 & Yang et al., 2010 \\
\hline Cocaine & Drug & CdSe/ZnS-aptamer & Atto 590 dye-labelled aptamer & - & - & - & 300 & $\begin{array}{l}\text { Freeman et al., } \\
2009 a\end{array}$ \\
\hline
\end{tabular}

${ }^{a}$ QDs from Life Technologies (Carlsbad, CA, USA)

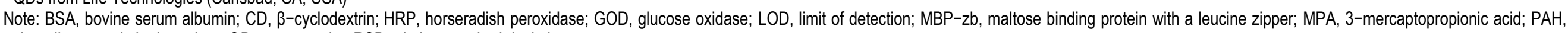
polycyclic aromatic hydrocarbon; $Q D$, quantum dot; RSD relative standard deviation. 
Table 7

Quantum dot based immunosensors and related immunoanalytical systems for haptens found in literature.

\begin{tabular}{|c|c|c|c|c|c|c|c|c|}
\hline Immunoassay type & Compound & Detection & QD & Sample & Recovery (\%) & RSD (\%) & LOD (ppb) & Reference \\
\hline Photoelectrochemical & Pentachlorophenol & Photocurrent intensity & CdSeTe & River water & $99-102$ & $6-7$ & 0.0003 & Kang et al., 2010 \\
\hline \multirow[t]{4}{*}{ Immunochromatographic } & 3,5,6-trichloropyridinol & Electrochemical & Qdot a & Rat plasma & $77-130$ & - & 1 & Zou et al., 2010 \\
\hline & Cotinine & Fluorescence & Qdot a & Human serum & $95-110$ & 6 & 1 & Nian et al. 2012 \\
\hline & Clenbuterol & Fluorescence & $\mathrm{QSH}^{\mathrm{b}}$ & - & - & - & 30 & Luo et al., 2011 \\
\hline & Ochratoxin A & Fluorescence & - & Water & - & 5 & 2 & Wang et al. 2011 \\
\hline \multirow[t]{2}{*}{ Flow injection } & Methyl-parathion & Fluorescence & CdTe & Water & $84-103$ & $0.2-7.0$ & 0.1 & Chouhan et al., 2010 \\
\hline & 2,4-dichlorophenoxyacetic acid & Fluorescence & CdTe & - & - & - & 0.3 & Vinayaka et al., 2009 \\
\hline Column gel & Benzo[a]pyrene & Fluorescence & CdTe & - & - & - & 0.005 & Beloglazova et al., 2011 \\
\hline Chip & 7-aminoclonazepam & Fluorescence & CdTe & Human urine & $90-101$ & 5 & 0.02 & Chen et al., 2009b \\
\hline
\end{tabular}

Technologies (Carlsbad, CA, USA)

Note: LOD, limit of detection; $Q D$, quantum dot; RSD, relative standard deviation. 


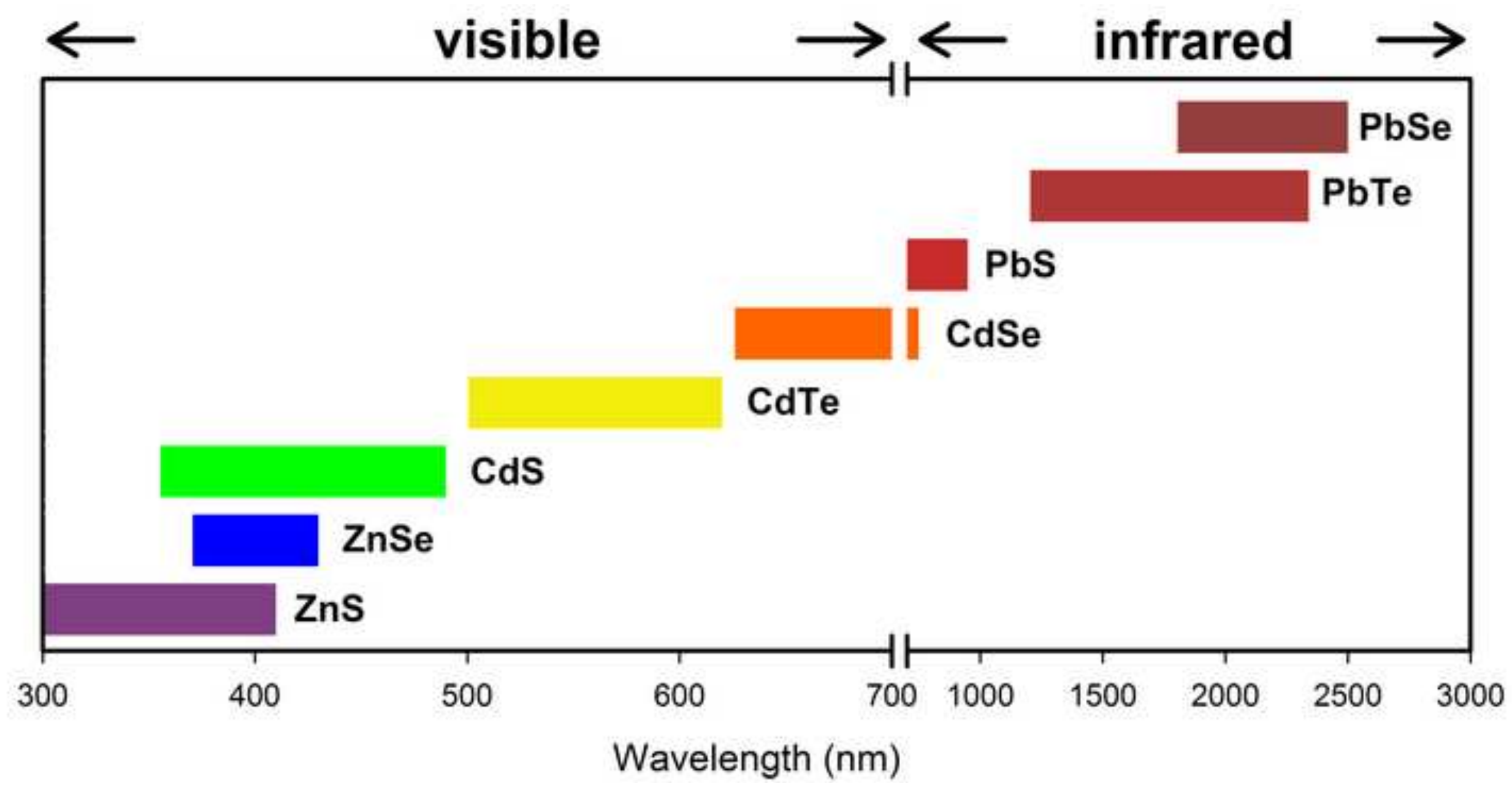




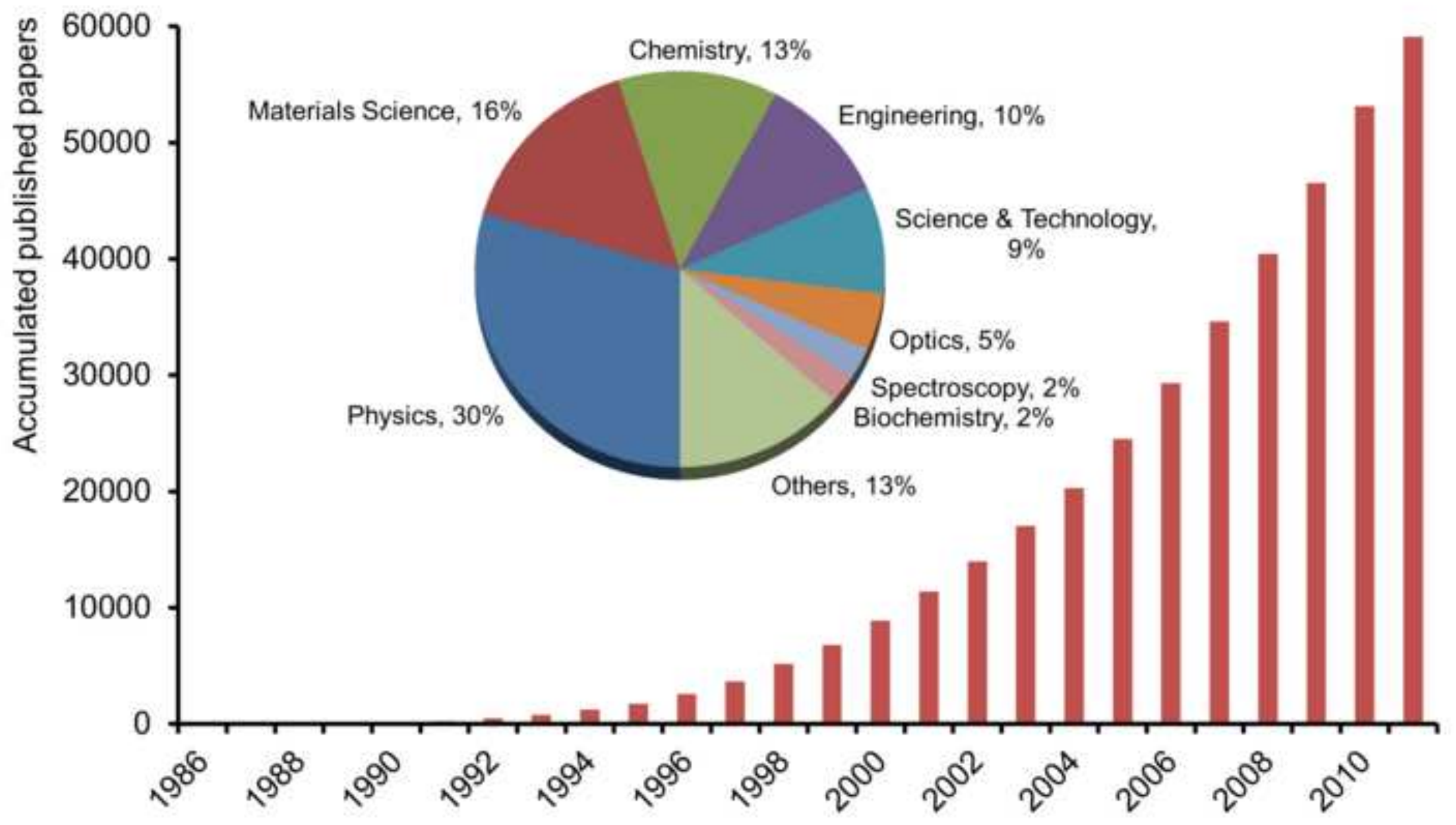




\section{A - Absorbance}
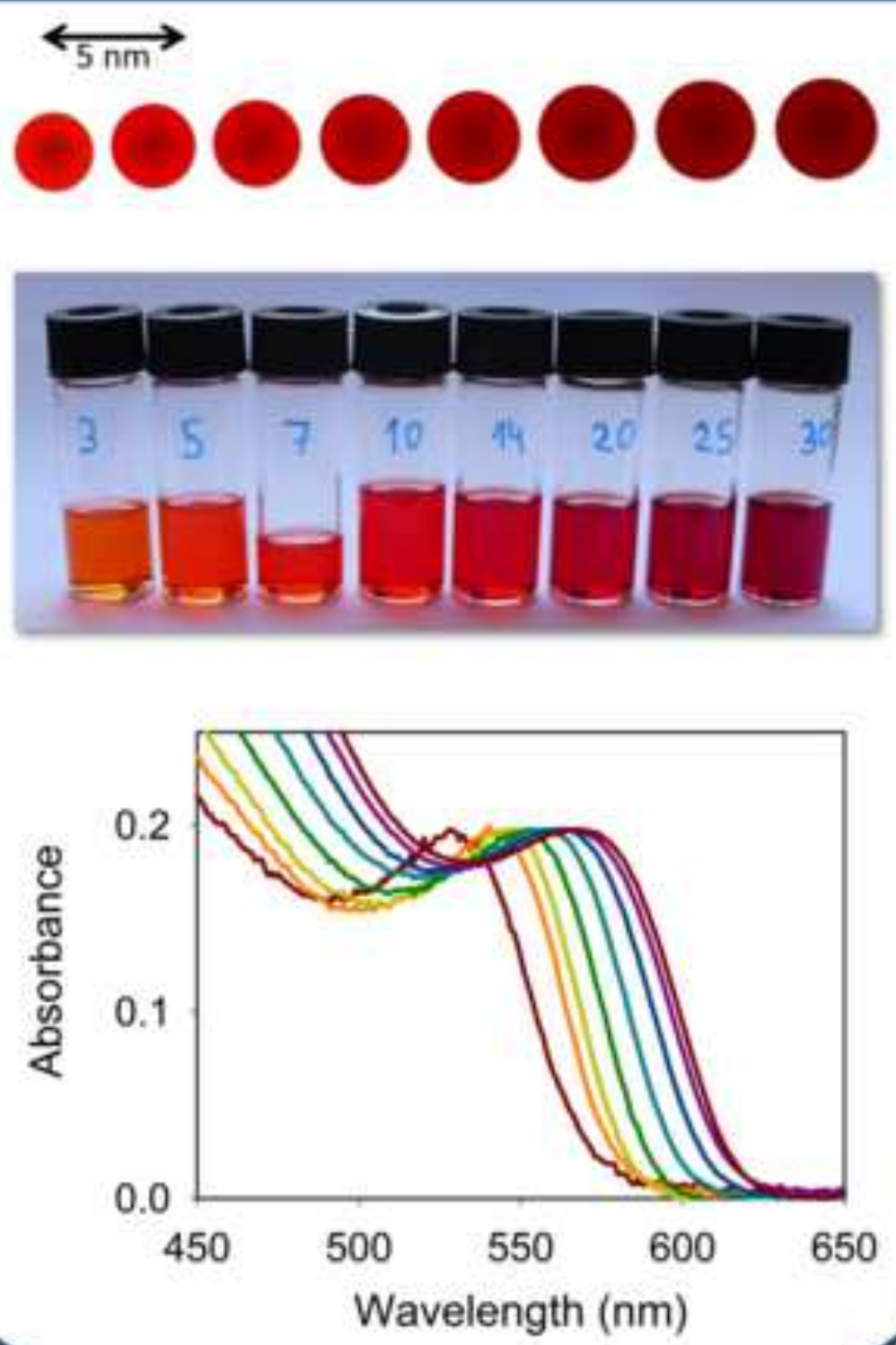

\section{B - Fluorescence}
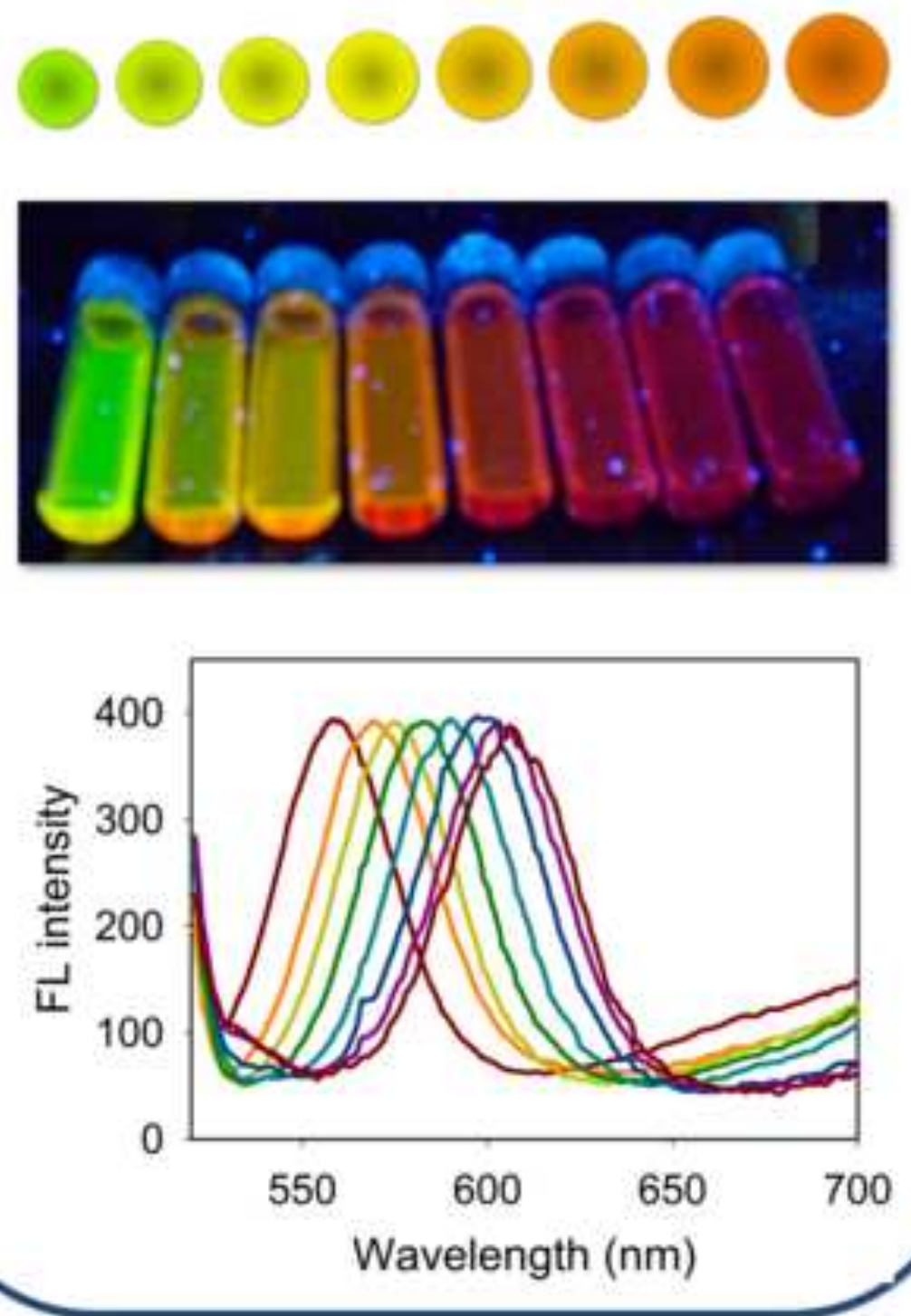

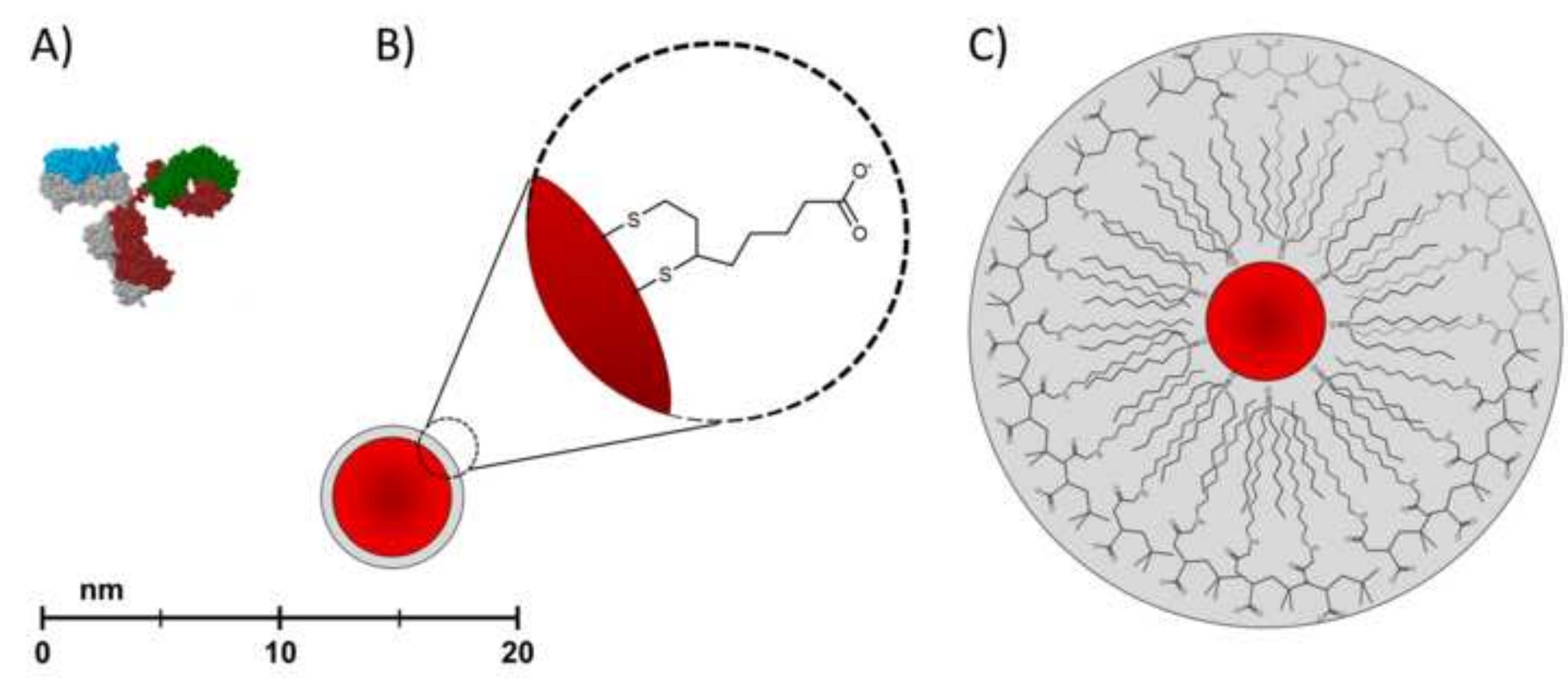

.
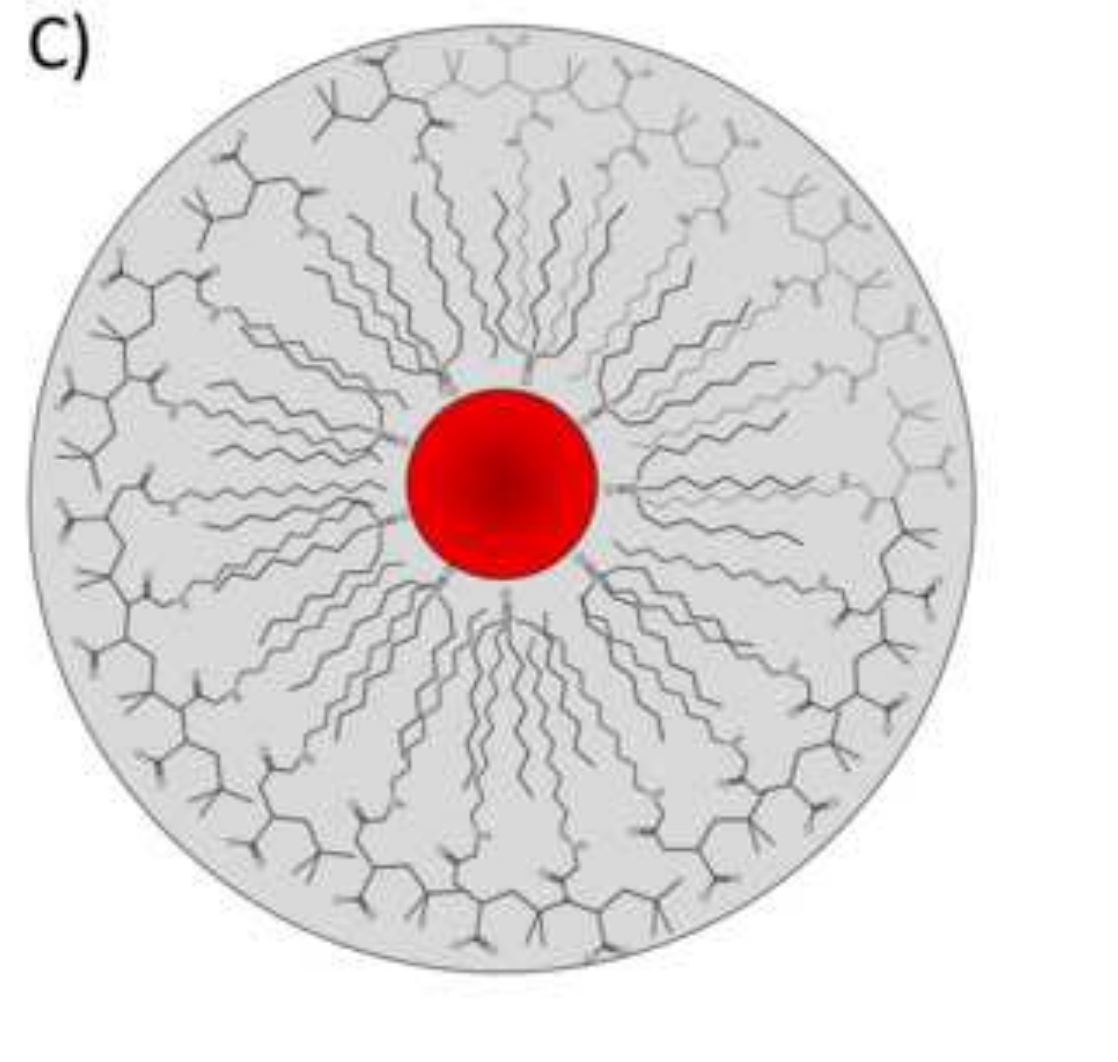
Click here to download high resolution image

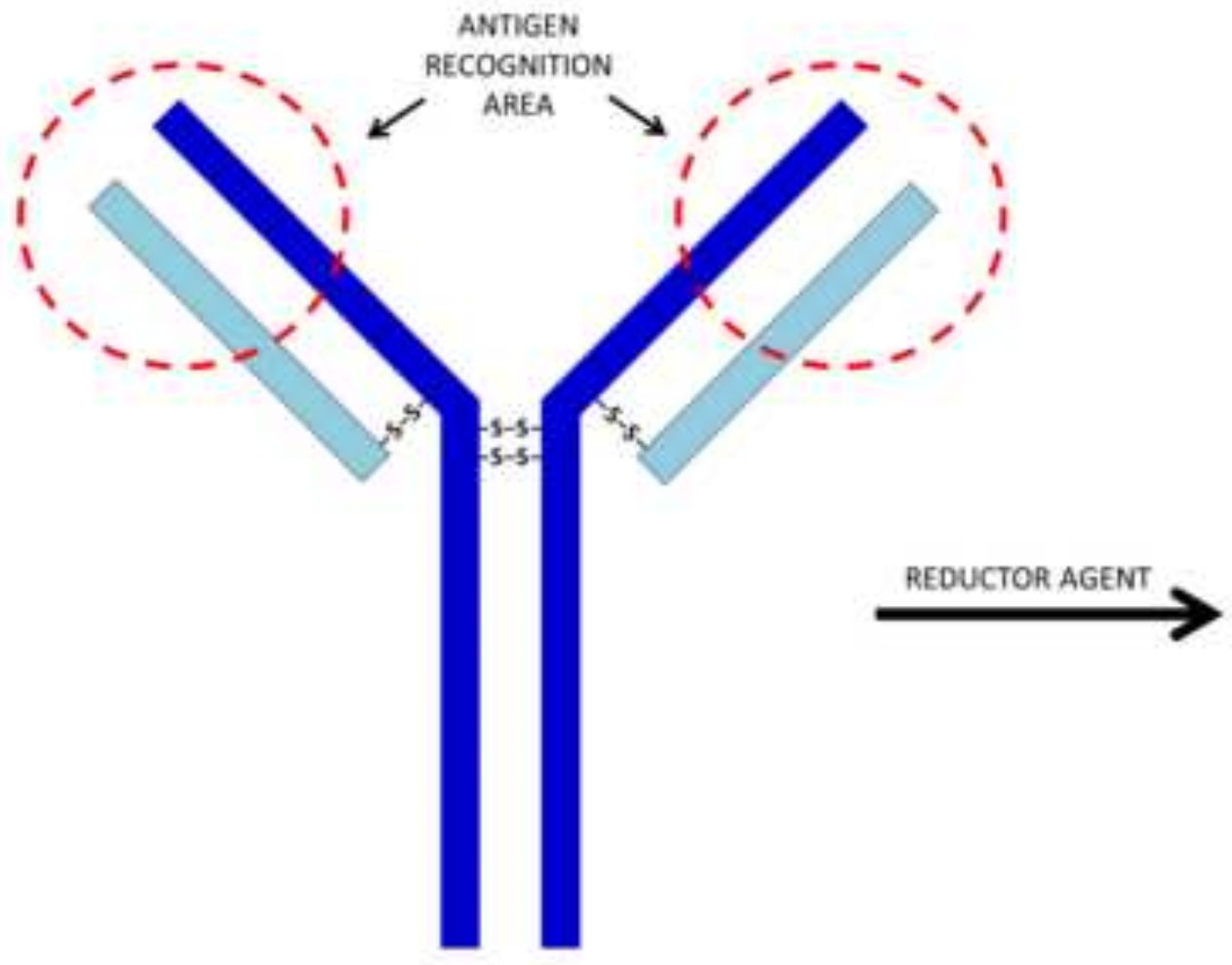

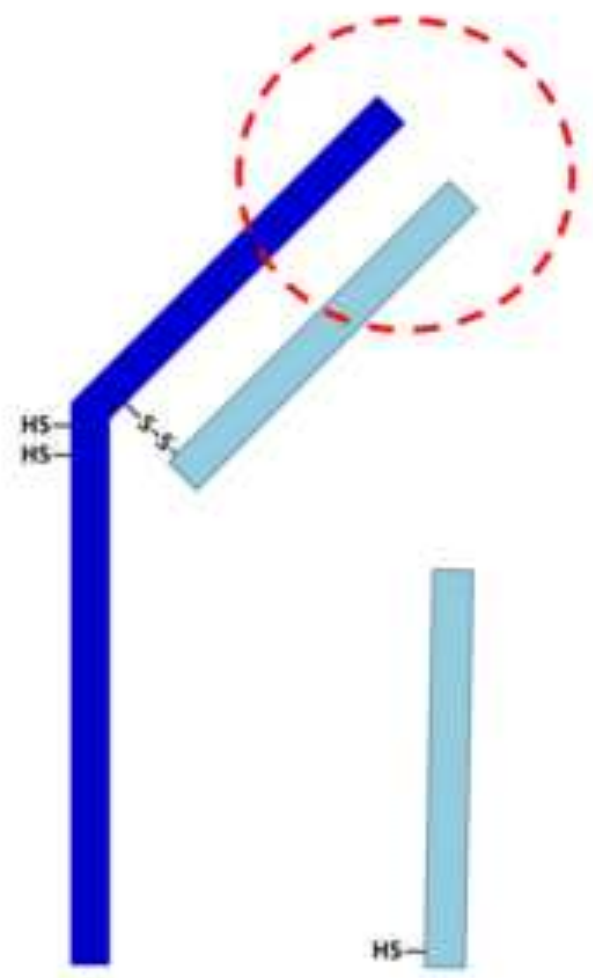

HEAVY-LIGHT CHAINS $75 \mathrm{kDa}$
UGHT CHAIN $25 \mathrm{kDa}$

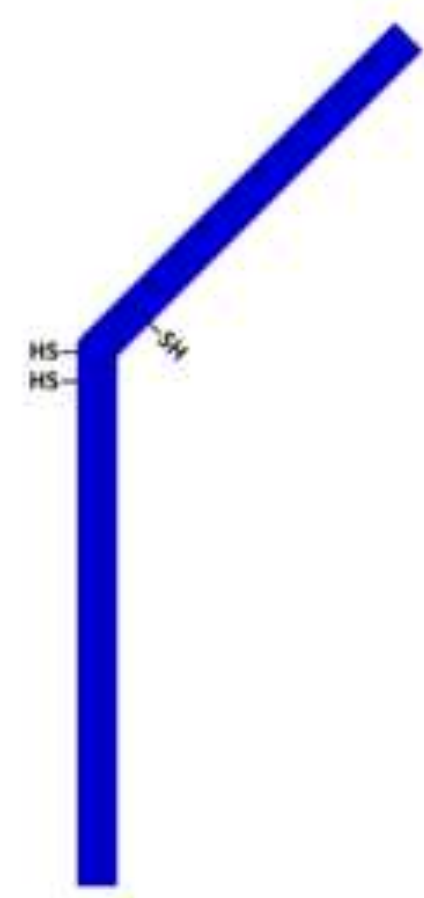

HEAVY CHAIN $50 \mathrm{kOa}$ 
Figure(s)
Click here to download high resolution image

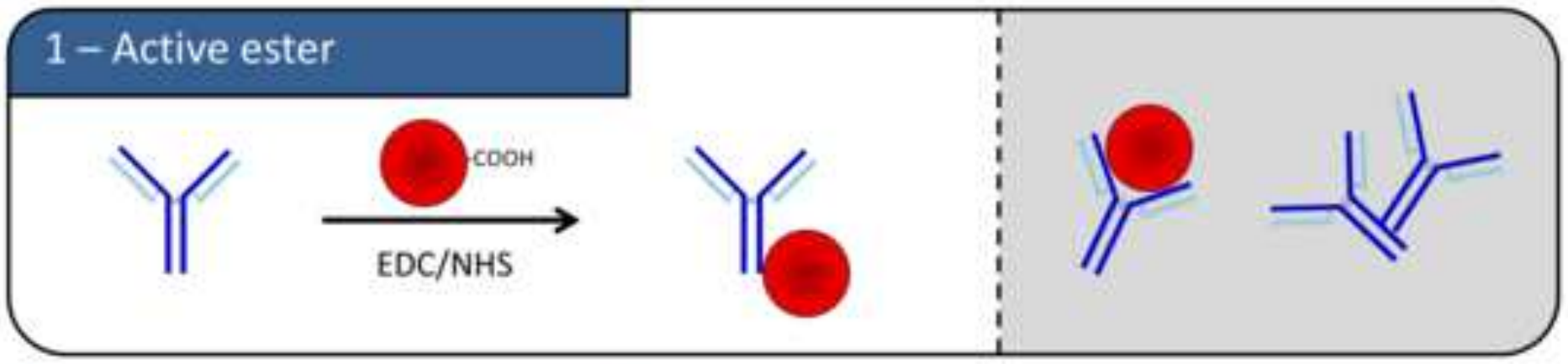

\section{2-Active maleimide}

Y
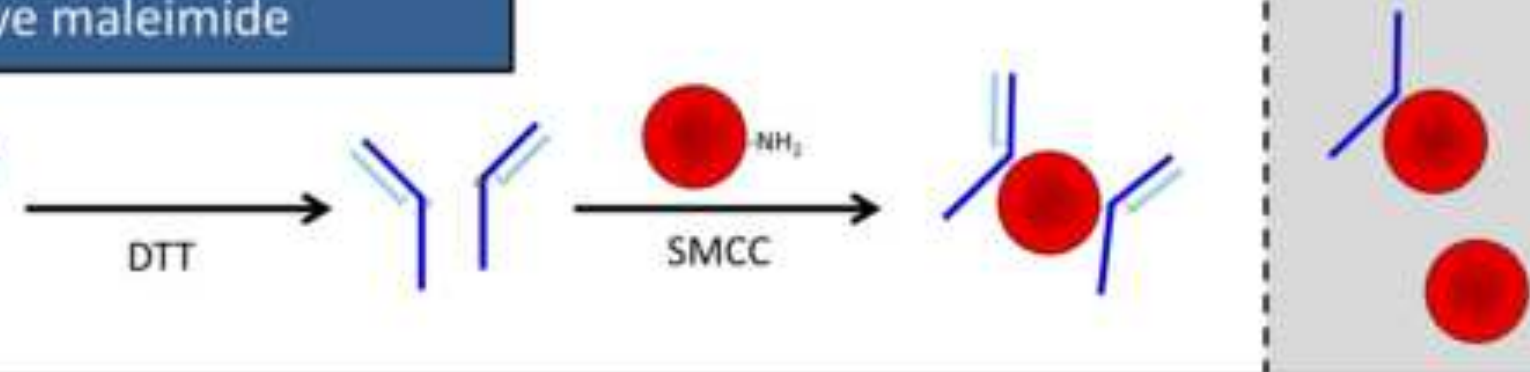

\section{3-Avidin bridge}
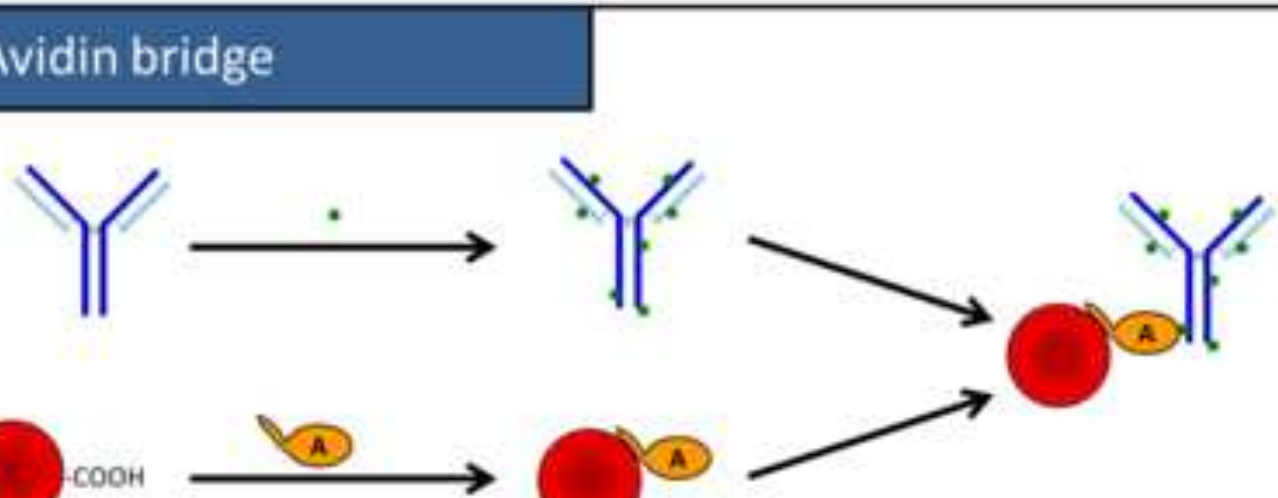

(A)
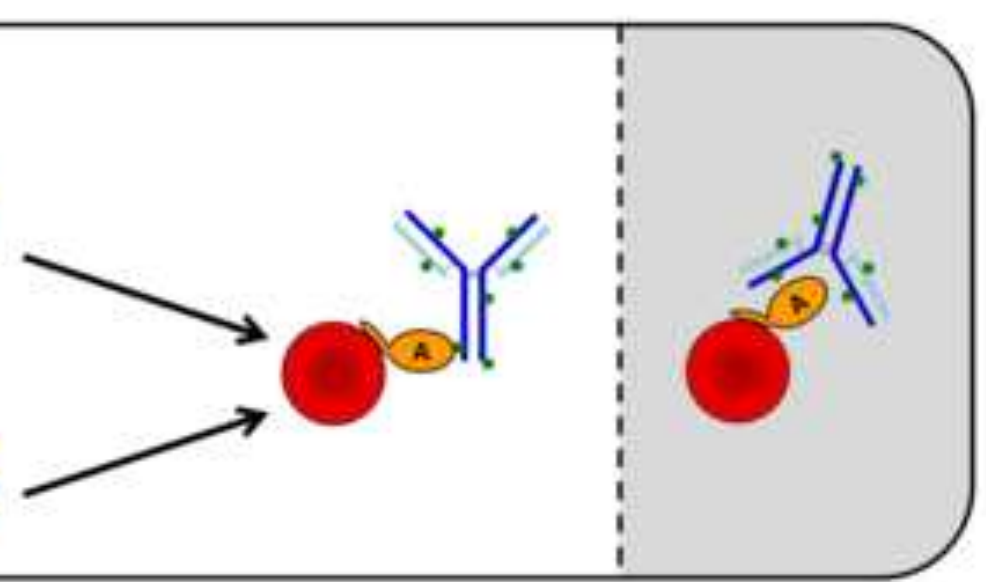

\section{4 - Protein $G$ bridge}
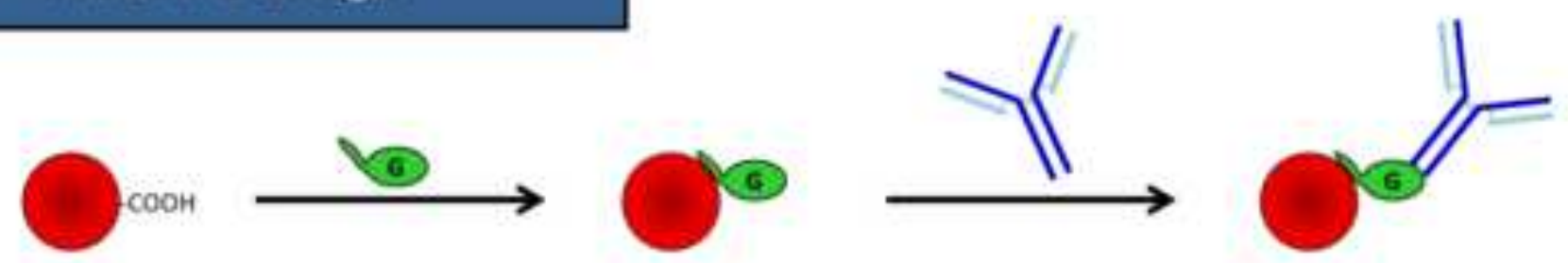

\section{5-Polyhistidine peptides}

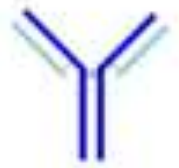

$$
\rightarrow \rightarrow \rightarrow \rightarrow
$$
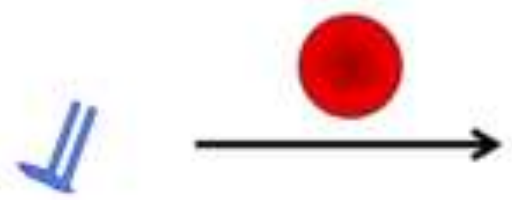

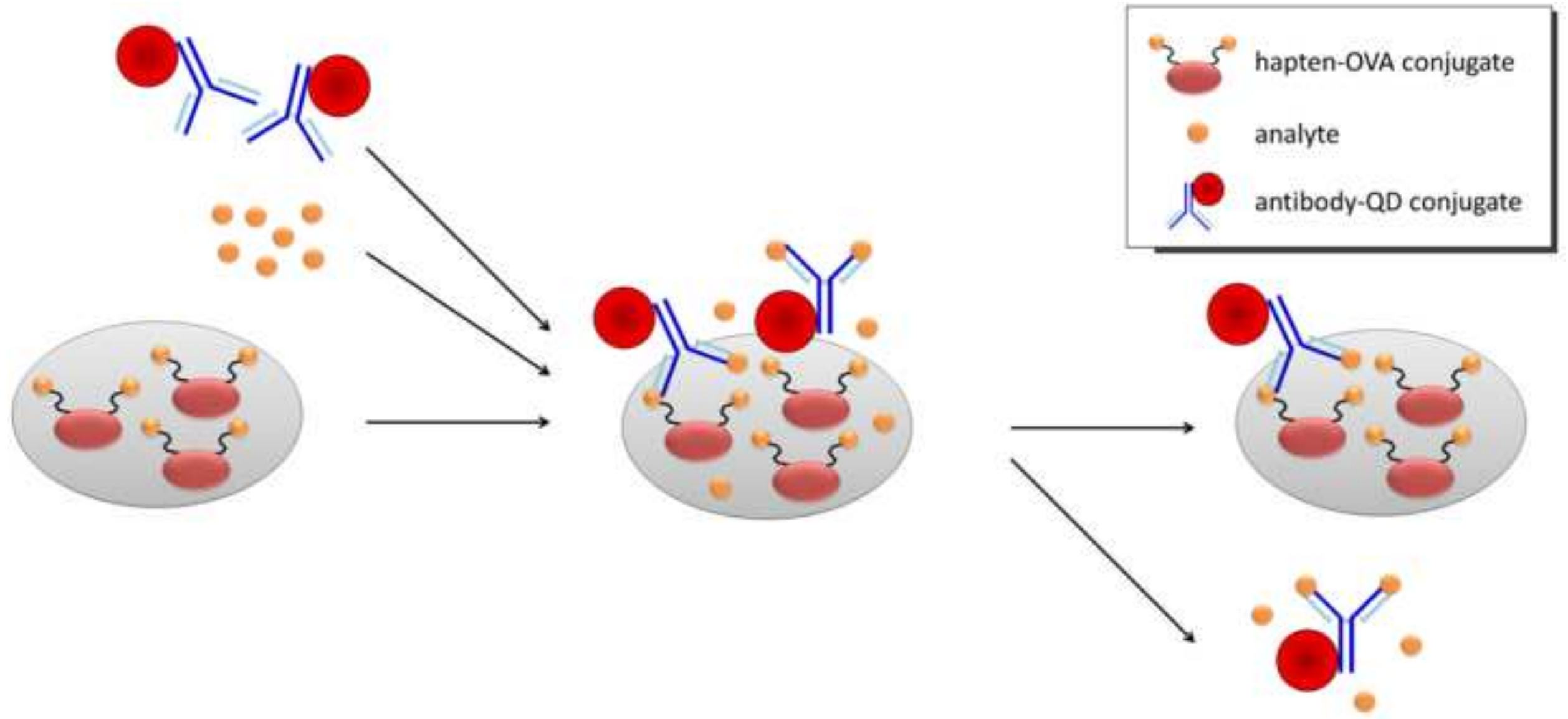

1) reagents addition

2) competitive reaction

3) plate washing 
A)
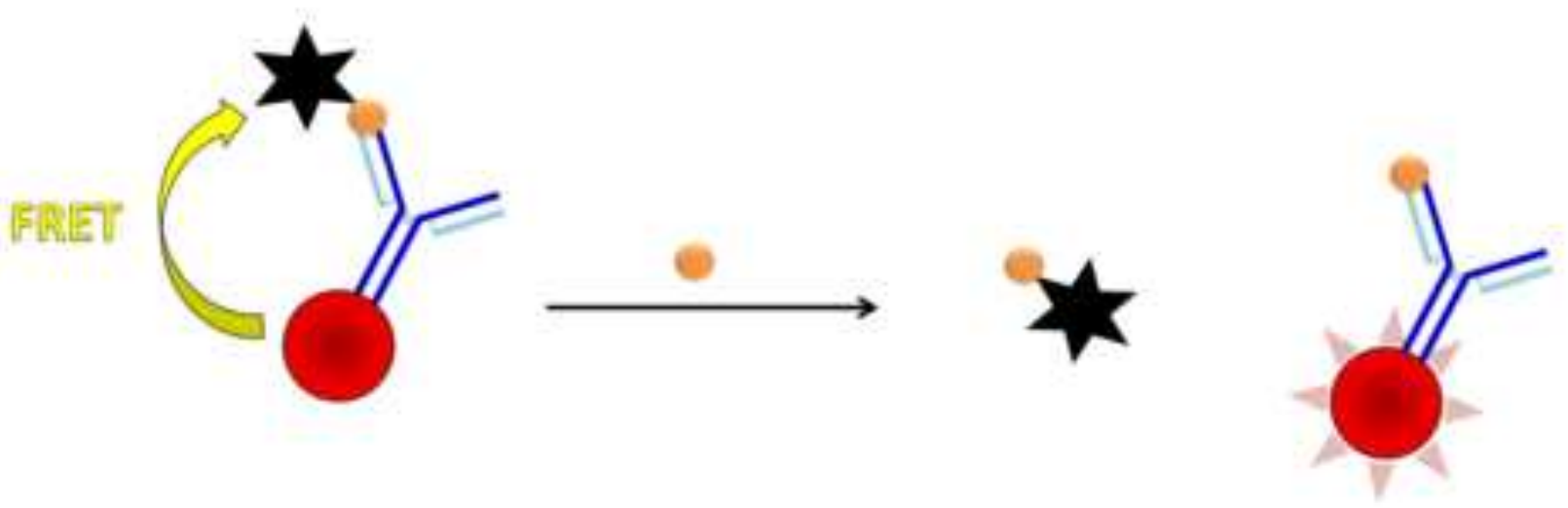

B)

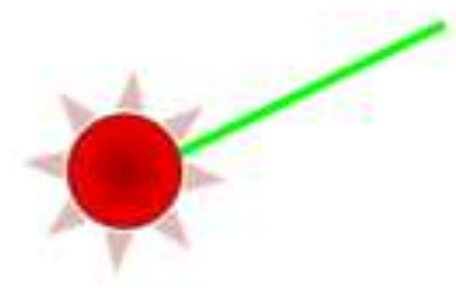

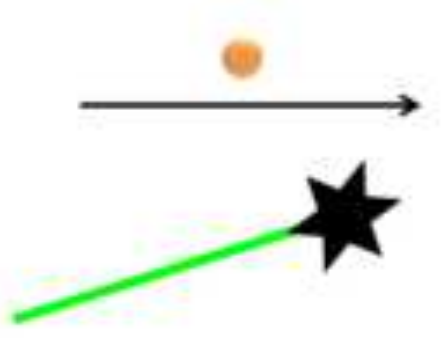

quantum dot

2 organic dye

- analyte

$\oiiint$ antibody aptamer 